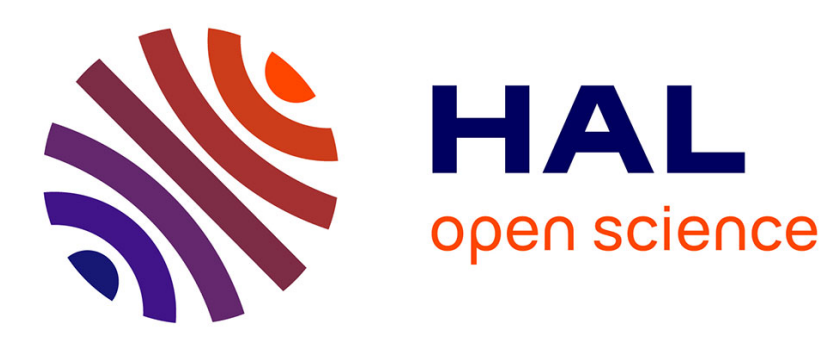

\title{
Helicene-based transition metal complexes: synthesis, properties and applications
}

Nidal Saleh, Chengshuo Shen, Jeanne Crassous

\section{To cite this version:}

Nidal Saleh, Chengshuo Shen, Jeanne Crassous. Helicene-based transition metal complexes: synthesis, properties and applications. Chemical Science, 2014, 5 (10), pp.3680-3694. 10.1039/C4SC01404A . hal-01077944

\section{HAL Id: hal-01077944 \\ https://hal-univ-rennes1.archives-ouvertes.fr/hal-01077944}

Submitted on 27 Oct 2014

HAL is a multi-disciplinary open access archive for the deposit and dissemination of scientific research documents, whether they are published or not. The documents may come from teaching and research institutions in France or abroad, or from public or private research centers.
L'archive ouverte pluridisciplinaire HAL, est destinée au dépôt et à la diffusion de documents scientifiques de niveau recherche, publiés ou non, émanant des établissements d'enseignement et de recherche français ou étrangers, des laboratoires publics ou privés. 


\title{
Helicene-based transition metal complexes: synthesis, properties and applications
}

\author{
Nidal Saleh, ${ }^{a}$ Chengshuo Shen, ${ }^{a}$ and Jeanne Crassous ${ }^{*}, a$ \\ In honour of Prof. Thomas J. Katz.
}

The coordination and/or organometallic chemistry of $\pi$-helicenic ligands appears as a powerful tool to generate multifunctional molecules displaying optimized chiroptical properties combined with new properties furnished by the metallic center. In this review, we relate the different examples that have been described in this field of research up to now.

\section{Introduction}

$[\mathrm{n}]$ Helicenes ${ }^{\dagger}$ are inherently chiral polycyclic molecules formed of ortho-fused aromatic rings that become configurationally stable when $n \geq 5$. Since the first synthesis of aza[5]helicenes in 1903, a large panel of organic carbo[n]helicenes and hetero[n]helicenes have been prepared either in their racemic or in their enantioenriched forms. ${ }^{1}$ In addition, their helical topology combined with their extended $\pi$ conjugated system provides helicenes with large optical rotation values and strong responses in electronic circular dichroism (ECD) as well as other properties such as non polarized and circularly polarized luminescence (CPL), conductivity, self-assembly, biological activity, catalytic activity, to name a few. ${ }^{2}$ Potential applications in materials science are non linear optical (NLO) devices, chiral waveguides, chiroptical switches, molecular motors, metamaterials, macroscopic fibers, 3D displays, transistors, ${ }^{3,4} \ldots$ The chemistry of these compounds has recently grown from the stage of an academic curiosity to an important field of research and several reviews have been dedicated to purely organic carbohelicenes or heterohelicenes. ${ }^{1,2,5-12}$ At the same time, transition metalbased helicenes are emerging as novel attractive chiral molecules for several reasons. Firstly, metals are powerful templates for assembling $\pi$-conjugated ligands into well defined molecular structures, simply by using the basic concepts of coordination and organometallic chemistry. ${ }^{13}$ Secondly, novel properties may appear when metallic ions are grafted onto $\pi$-helical structures. ${ }^{14}$ Finally, coordination and organometallic chemistry offer simple ways to tune the optical, chiroptical and electronic properties of the $\pi$-ligands since the topology together with the nature of the metal-ligand and ligand-ligand interactions can be readily modified by varying the metal center, its associated coordination sphere geometry, its redox state, ... This review is divided into two parts: organometallic helicenes, i.e. helicenes bearing metal-carbon $\sigma$ bonds, and heterohelicene ligands for coordination chemistry. We focus here on molecular systems; examples involving deposition of organic helicenes onto metal surfaces or nanoparticles are not presented.

\section{A Organometallic helicenes}

Organometallic helicene derivatives, i.e. helicenes bearing a $\mathrm{C}-\mathrm{M} \sigma$ bond, are becoming more and more attractive molecules in materials science. ${ }^{13,14}$ For instance, original carbon-rich architectures such as organometallic polymers can be targeted. In addition, the incorporation of heavy metal centers within the helical $\pi$-conjugated system can significantly modify the photophysical properties of the helicene derivative due to strong spin-orbit coupling. Finally, the helicene core can adopt a non-innocent behaviour when grafted to a redox-active metal possessing efficiently interacting orbitals. As explained in the following examples, all these aspects lead to innovative applications such as responsive chiral polymers, circularly polarized phosphorescence emitters, or chiroptical switching devices.

\section{A. 1. Helicenic metallocenes}

\section{A.1.1. Transition metal complexes with $\eta^{5}$-helicenic ligands}

The organometallic chemistry of helicenes was pioneered by Prof. Thomas Katz and coworkers in the late 1970's. The original idea was to synthesize helical metallocene oligomers by reacting either cobalt or iron ions with helicene ligands of appropriate lengths and bearing terminal cyclopentadiene moieties. In 1978, they showed that achiral bis-cobaltocenium- 
type (1) and bis-ferrocene-type (2) closed structures were formed instead of oligomers when using respectively short [4] or [5] helicene proligands (Scheme 1). ${ }^{15, \uparrow}$

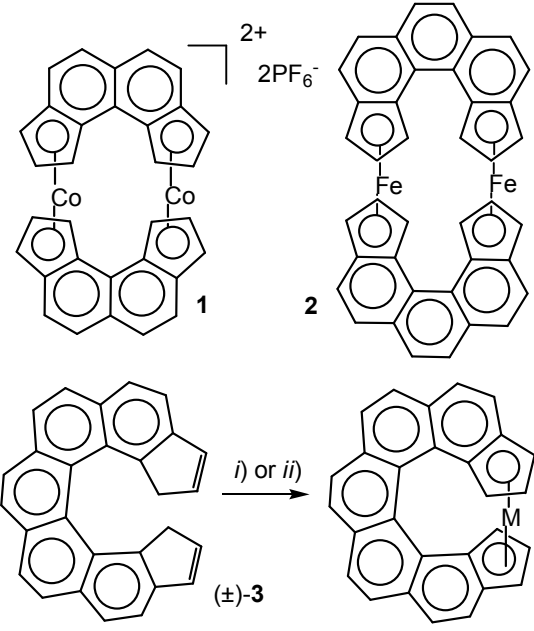

$( \pm)-4: M=F e$

$( \pm)-5: M=\mathrm{Co}^{+} \mathrm{PF}$

Scheme 1. First example of organometallic $\mathrm{Fe}(\mathrm{II})$ and $\mathrm{Co}$ (III) complexes bearing $\eta^{5}$-helicenic ligands. i) ${ }^{t} \mathrm{BuLi}, \mathrm{FeCl}_{2}$; ii) $\mathrm{CoBr}_{2}$, oxidation, then $\mathrm{NH}_{4} \mathrm{PF}_{6} .{ }^{15,16}$

Longer racemic [7]helicene proligand 3 possessed the appropriate size to place the two cyclopentadienyl rings in front of each other thanks to a full turn of the helix. Then, reaction with $\mathrm{FeCl}_{2}$ led to the formation of closed structure 4 (Scheme $1)^{16}$ in which the two terminal five-membered rings coordinate an iron atom in between. The X-ray crystallographic structure of complex 4 was reported in $1983 .{ }^{17}$ Compared to the ligand, it showed a dramatic decrease of the dihedral angle between the two terminal rings from $69.1^{\circ}$ to $19.8^{\circ}$. In 1986 , enantioenriched proligand $M-(-)-3^{\prime},{ }^{19}$ a structural isomer of $\mathbf{3}$, was prepared by a diastereoselective photocyclization process of a precursor bearing a chiral silyl ether in one of the terminal rings, followed by dehydration (Scheme 2). ${ }^{18}$ Then, reacting enantioenriched $M$-(-)-3' with either $\mathrm{FeCl}_{2}$ or $\mathrm{CoBr}_{2}$ /oxidation yielded enantioenriched helical ferrocene $M-(-)-4\left([\alpha]_{D}=-3700\right.$, ee $62 \%$, THF, $C 0.022$,) and the cobaltocenium analogue $M-(-)-$ $5[\alpha]_{578}=-7100,{ }^{*}$ acetone, $C 0.0045$, ee 95\%). Such complexes display huge specific rotations, probably as a consequence of the unbroken conjugation throughout the whole molecule. Their ECD spectra also display strong molar ellipticities corresponding to the classical strong $\mathrm{CD}$-active band around $330 \mathrm{~nm}$ (molar ellipticities for $M-(-)-4:[\theta]_{335}=-1.8210^{5}$ deg. $\mathrm{cm}^{2} / \mathrm{dmol}$ at $335 \mathrm{~nm}$ in THF, for $M-(-)-3:[\theta]_{330}=-2.3310^{5}$ deg. $\mathrm{cm}^{2} / \mathrm{dmol}$ at $330 \mathrm{~nm}$ in $\mathrm{CH}_{3} \mathrm{CN}$ ) accompanied with lower energy ECD-active bands probably corresponding to charge transfer transitions involving the metallic ion. ${ }^{18}$ Iron and cobalt complexes bearing a bis- $\eta^{5}-[7]$ helicenic ${ }^{\dagger}$ ligand were the first examples of non racemic organometallic helicenes described in the literature. Note that such conjugated arrays with a helical structure might display interesting electrical conducting properties.

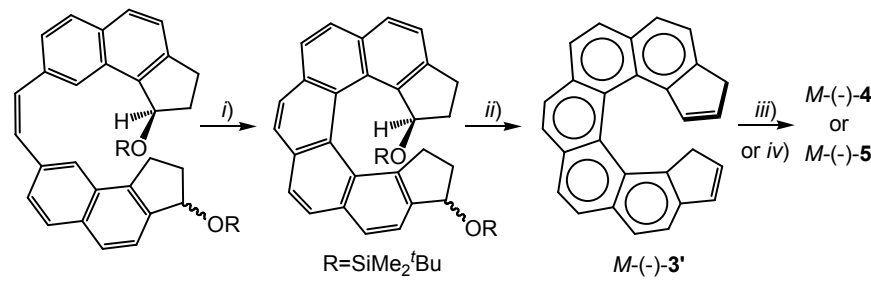

Scheme 2. Synthesis of enantioenriched organometallic Fe(II) $(M-(-)-4)$ and $\mathrm{Co}$ (III) $(M-(-)-5)$ helicenic complexes. i) $h v, \mathrm{I}_{2}$, propylene oxide; ii) TsOH, $\mathrm{C}_{6} \mathrm{H}_{6}$; iii) ${ }^{t} \mathrm{BuLi}$, $\mathrm{FeCl}_{2}$; iv) $\mathrm{CoBr}_{2}$, oxidation, then $\mathrm{NH}_{4} \mathrm{PF}_{6} .{ }^{18}$

In 1993, Katz's group reported three other cobalt helicene complexes, i.e. the $\mathrm{Co}^{\mathrm{III}}-[8]$ helicene $P-(+)-7$, the $\mathrm{Co}_{2}{ }^{\mathrm{III}}-$ [9]helicene $P-(+)-8$ and the Co ${ }^{\text {III }}$-bis[8]helicene $M-(-)-9$ (Figure 1). ${ }^{20}$ The specific rotation of $P-(+)-7$ is $4500,{ }^{*}$ which is lower than for its [8]helicene proligand (6300), while that of $(M, M)-(-$ )-9 is -13600 , slightly more than twice the specific rotation of the proligand. Complex $P-(+)-8$ was prepared from enantioenriched [9] helicene $P-(+)-6$ (see $M-(-)-6$ on Scheme 3) capped with two cyclopentadiene terminal rings synthesized via a diastereoselective double photocyclization of an appropriate chiral bis-ether. ${ }^{21}$ Its specific rotation (8200), is similar to that of its bis-indenyl-[9] helicene precursor (7800). However, in order to be able to compare different organometallic helicenes with different constitutions, one needs to consider the molar rotation (MR) ${ }^{*}$ which takes into account the molecular weight of the compounds (see Table 1). Doing this, one can see that the influence of the metallic center on the chiroptical properties is significant. This increase in the MR values upon cobalt complexation can be explained by the presence of ECD-active bands in the low-energy region ( $>480 \mathrm{~nm}$ ) that involve charge transfers between the metal orbital and the $\pi$-ligand (vide infra) and that significantly contribute to the MR value. Cyclic voltammetry of complex $\mathbf{8}$ was used in order to see if a communication existed between the two Co ions through the helicenic bridge. Two reversible $\mathrm{Co}^{\mathrm{II}} / \mathrm{Co}^{\mathrm{II}}$ reduction waves separated by $130 \mathrm{mV}$ were observed, indicating a possible weak interaction. However UV-vis, CD and EPR spectroscopies of one-electron reduced species revealed that the delocalization through the whole molecule is almost ineffective and that nearinfrared inter-valence transitions were absent. ${ }^{22}$

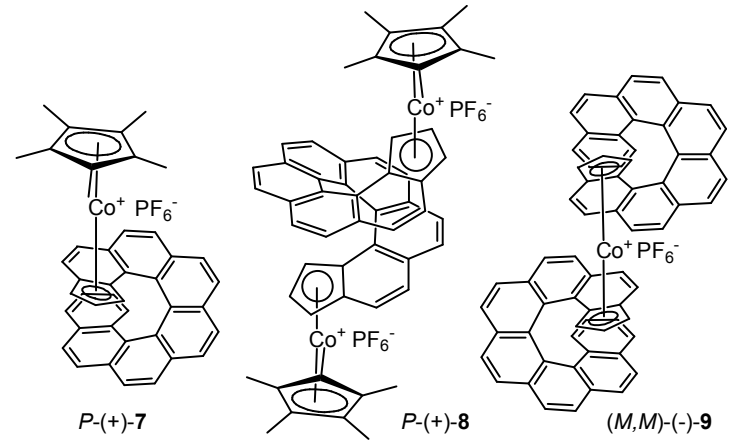


Figure 1. a) Chemical structures of diverse cobaltocenium complexes based on [8] and [9] helical mono- or bis-indenyl ligands. ${ }^{20}$

Table 1. Specific and molar rotations ${ }^{*}$ of selected helicenic ligands and complexes.

\begin{tabular}{ccc}
\hline Sample/length (n) & {$[\alpha]_{D}{ }^{*}$} & {$[\phi]_{D, \text { max }}{ }^{\mathrm{a},{ }^{*}}$} \\
\hline$M-\mathbf{6}^{21,23}$ & -7800 & -35460 \\
$P \mathbf{- 7}^{23}$ & +4500 & +33975 \\
$P \mathbf{- 8}^{23}$ & +8200 & +92740 \\
$M-\mathbf{9}^{23}$ & -13600 & -140760 \\
\hline
\end{tabular}

${ }^{\text {a }}$ Considering $100 \%$ enatiopurity.

Katz et al. finally succeeded in preparing helical metallocene oligomers $M$ - or $P \mathbf{- 1 0 a}, \mathbf{b}$ from [9]helicene $M$ - or $P$-6 (Scheme 3). ${ }^{21}$ Indeed, the short oligomeric colbatocenium complex (-)-10a containing 2 to 4 helicenic units and linked by $\mathrm{Co}^{\mathrm{III}}$ atoms, as identified by fast atom bombardment mass spectrometry and elemental analyses (average molecular weight $1.910^{3}{\mathrm{~g} . \mathrm{mol}^{-1}}^{-1}$, was prepared from bis-indenyl[9] helicene ${ }^{\dagger} M$ (-)-6 and its chiroptical properties were studied. This optically active oligomer displays a very large $[\alpha]_{D}(-26000$ for $100 \%$ ee), ${ }^{*}$ which is 4.1 times greater than the proligand $M$-(-)-6. Its circular dichroism was also investigated and the molar ellipticities at 474 and $263 \mathrm{~nm}\left([\theta]=-8.410^{5} \mathrm{deg} \cdot \mathrm{cm}^{2} / \mathrm{dmol}\right.$ and $-3.310^{5} \mathrm{deg} . \mathrm{cm}^{2} / \mathrm{dmol}$, assuming the molecular weight to be $1.910^{3}$ ) were found 7.2 and 6.0 times larger than the corresponding ECD-active bands in $M$-(-)-6. Isoelectronic ferrous complex $(+)-\mathbf{1 0 b}$ was also prepared and showed huge specific rotation $\left([\alpha]_{D}=27000\right.$, benzene, $\left.C 0.1\right),{ }^{*}$ but it was impossible to obtain it in chemically pure form. ${ }^{23}$
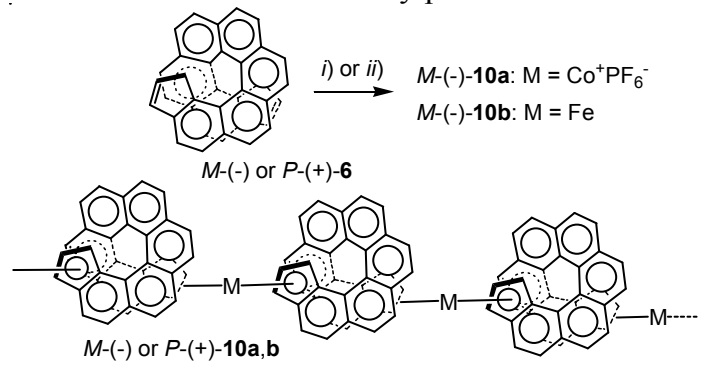

Scheme 3. First example of oligomeric organometallic $\mathrm{Co}(\mathrm{III})$ and $\mathrm{Fe}(\mathrm{II})$ complexes $M-(-)-10 \mathbf{a}$, b bearing bis- $\eta^{5}$-helicenic ligands. $\left.i\right) \mathrm{CoBr}_{2}$, oxidation, then $\mathrm{NH}_{4} \mathrm{PF}_{6} ;$ ii) ${ }^{t} \mathrm{BuLi} \mathrm{FeCl}_{2}{ }^{21}$

The cobaltocenium oligomers such as $\mathbf{1 0 a}$ were extensively studied and it was shown that oligomers of different lengths can be obtained depending on the solvent used for the oligomer synthesis. Toluene gave heptamers, the longest systems obtained due to increased solubility. These compounds exhibited strong chiroptical responses, with specific rotations reaching 32000-34000 (acetone, $C$ 0.002) and strong $C D$ active bands with $\Delta \varepsilon$ values between $300-1200 \mathrm{M}^{-1} \mathrm{~cm}^{-1}{ }^{23}$ However, these values corresponded to no more than the addition of several cobaltocenium units, which suggested that no efficient electronic interaction occured between each unit (not a mixedvalence system). ${ }^{21}$ This was further confirmed by the cyclic voltammetry which displayed a large $\mathrm{Co}{ }^{\mathrm{III}} / \mathrm{Co}^{\mathrm{II}}$ reduction wave at a potential similar to the corresponding mononuclear and dinuclear species. However and very interestingly, the electrolytic reduction of cobaltocenium oligomers in acetonitrile on a Pt electrode yielded the formation of a film which appeared conductive. This film could be reversibly oxidized and dissolved. Another interesting aspect is the reversible reduction and oxidation of these oligomers in solution using respectively cobaltocene in excess and air. Significant changes were observed in the CD spectrum of 10a which interconverts between the fully oxidized and the fully reduced species with the presence of several isosbestic points (Figure 2). In fact, it can be considered as the first example of helicene-based redox-triggered $\mathrm{CD}$-active switch (vide infra)!

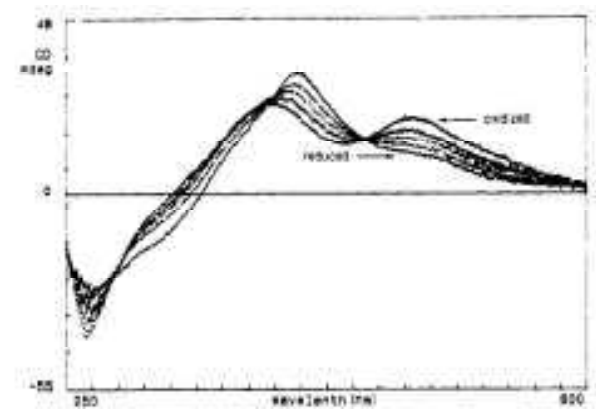

Figure 2. Modification of the $C D$ spectrum of 10 a upon reduction and oxidation Reproduced with permission from ref. 23.

Organometallic pentahelicene analogues 11-13 were prepared by Thiel et al. from dibenzo[c,g]fluorenide (Dbf) acting as a cyclopentadienide ligand (Figure 3). However, these ferrocene, cobaltocenium and ruthenocene-type complexes were not resolved into pure enantiomers and their configurational stability was not studied. ${ }^{24-26}$
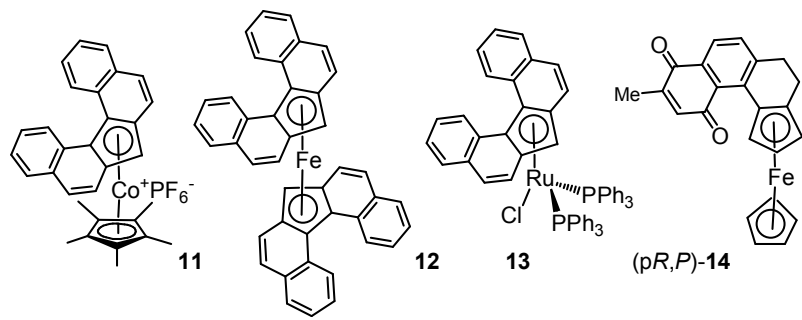

Figure 3. Chemical structures of metallocene complexes 11-13 bearing one or two Dbf ligands, ${ }^{24-26}$ and ferrocene complex $14 .^{27}$

Finally, enantiopure ferrocen[4] helicenequinone $(p R, P)-\mathbf{1 4}$ showing both planar and helical chirality was recently prepared by Carreno, Urbano et al. through a kinetic resolution process using an enantioselective Diels-Alder reaction. ${ }^{27}$ This chiral compound did not exhibit the typical CD signature of helicenes but a negative CD-active band at $621 \mathrm{~nm}$ was observed corresponding to an intramolecular charge transfer from the ferrocene donor to the quinone acceptor and inducing strong specific rotation at $589 \mathrm{~nm}\left([\alpha]_{D}=-1660, \mathrm{CHCl}_{3}, C 0.001\right.$, ee $95 \%)^{*}$ 


\section{A.1.2. Transition metal complexes with $\eta^{6}$-helicenic ligands}

In 2012, Alvarez et al. examined the $\eta^{6}$-coordination of iridium(III) and ruthenium(II) to hexahelicene 15, 2,15dimethyl-hexahelicene $\mathbf{1 6}$ and 2,15-dibromo-hexahelicene 17 (Scheme 4). ${ }^{28}$ By reacting these helicenes with $\left[\mathrm{Cp}^{*} \mathrm{IrCl}_{2}\right]_{2}$, the $\eta^{6}$-iridium complexes were obtained as isomeric mixtures 18ac, 19a-c and 20a-c, as evidenced by ${ }^{1} \mathrm{H}$ and ${ }^{1} \mathrm{H}-{ }^{1} \mathrm{H}$ NOESY NMR experiments, which after several days led to the more thermodynamically stable complexes 18a, 19a, and 20a. In all cases, it was therefore observed that the metal fragment coordinates to the terminal ring of the helicene ligand, with a clear preference to coordinate to the $\mathbf{C}$ ring at the beginning of the reaction. Furthermore, while the coordination to ring $\mathbf{C}$ was fast (a few seconds), the isomeric process leading to complexation to ring A was slow (several days). Such movement along the helical backbone was proposed to proceed via two routes: either through a migration of the metal cationic unit walking over the helix surface or through a dissociation/association process. DFT calculations showed that the migration of iridium walking over the surface involves a haptotropic rearrangement from $\eta^{6}$-arene to $\eta^{3}-\mathrm{C}=\mathrm{C}-\mathrm{C}$ followed by a new haptotropic migration to another $\eta^{6}$-arene on the exo side. An earlier theoretical study by Sola et al. on the migration of tricarbonylchromium on a tetrahelicene also suggested this haptomigration and showed the preference for the metal to bind to the outer rings which are less substituted and more aromatic. ${ }^{29}$ From a general viewpoint, the presence of an alkyl substituent in the helicene ligand facilitates the coordination and the formation of $\eta^{6}$-arene complexes. By following the same synthetic strategy with more equivalents of $\left[\mathrm{Cp}^{*} \mathrm{IrCl}_{2}\right]_{2}$, the bimetallic $\eta^{6}$-Ir complex 21 (Figure 4) was obtained; it corresponds to the maximum number of metal units that could be bonded. Finally, the reaction of ligand 16 with $\left[\left(\eta^{6}-\right.\right.$ cymene) $\left.\mathrm{RuCl}_{2}\right]_{2}$ yielded the monometallic $\eta^{6}$-Ru complex 22 whose structure was ascertained by X-ray crystallography which showed a decrease of the helicene's helical pitch when coordinating the metal. ${ }^{28}$

\section{A.1. 3. Helicenes acting as molecular tweezers}

The ability of carbo[7]helicene to act as a chiral "molecular tweezer" was examined by several groups. In 2006, Saini and Deb reported a computational study of the interaction of carbo[7]helicene with alkali cations. The two terminal benzene rings were reported to act as "crocodile's jaws" that can chelate

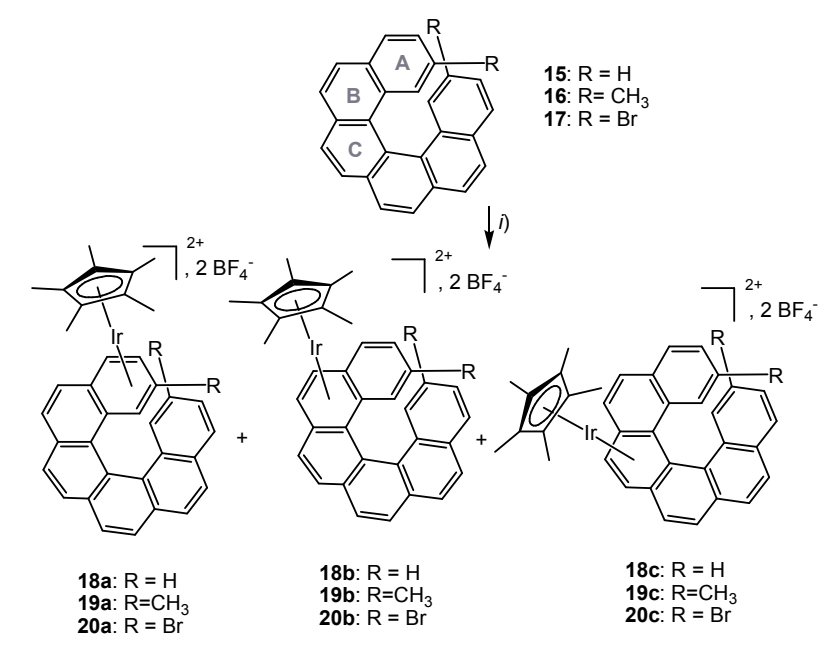

Scheme 4. One-pot reaction between $\left[\mathrm{Cp}^{*} \mid \mathrm{ICl}_{2}\right]_{2}$ and helicenes 15-17 to form the three isomeric complexes $\mathbf{a}, \mathbf{b}$ and $\mathbf{c}$. $i)\left[\mathrm{Cp} * \mathrm{IrCl}_{2}\right]_{2}, \mathrm{AgBF}_{4}, \mathrm{CD}_{3} \mathrm{NO}_{2} .{ }^{28}$

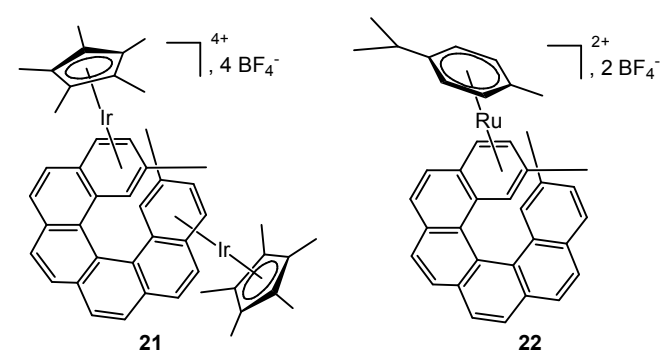

Figure 4. Bimetallic $\eta^{6}$-Ir complex $\mathbf{2 1}$ and monometallic $\eta^{6}$-Ru complex $\mathbf{2 2}$ bearing 2,15-dimethyl-[6]helicene ligand $16^{28}$

a cation. The stability of complexes increased with the order $\mathrm{Na}^{+}>\mathrm{K}^{+}>\mathrm{Cs}^{+}{ }^{30}$ Later on, Johansson and Patzschke theoretically investigated the trapping of metallic ions $(\mathrm{Cr}, \mathrm{Mo}, \mathrm{W})$ by carbo[7]helicene. ${ }^{31}$ The same year, an $\operatorname{Ag}(\mathrm{I})$ complex of carbo[7]helicene was prepared by Fuchter et al.. ${ }^{32}$ This complex was characterized by X-ray crystallography of a racemic sample (Figure 5a) which evidenced that the $\mathrm{Ag}^{+}$cation binds at the edge of the two terminal rings of the helicene through $\eta^{2}-\mathrm{C}=\mathrm{C}$ binding modes. Such kind of complexes may have potential interest for the construction of solid-state devices such as electric conductors. ${ }^{33}$

a)

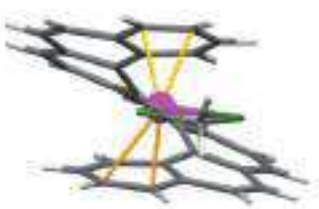

b)

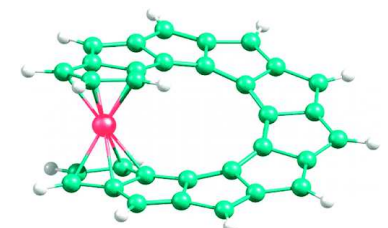

Figure 5. a) X-ray structure of a $\mathrm{Ag}^{\prime}$-[7]helicene complex with one coordinated $\mathrm{CH}_{2} \mathrm{Cl}_{2}$ molecule. ${ }^{32}$ b) Theoretical molecular structure of a ferrocene constructed from 10 fused cyclopentadienes. ${ }^{34}$ Adapted with permission from ref. 32 and 34 . 
In 2009, a hypothetical ferrocene formed from a polycyclic hydrocarbon ligand bearing 10 fused cyclopentadiene rings was considered as a potentially stable helicoid complex (Figure 5b). ${ }^{34}$ Note that the ferrocene $\mathbf{4}$ and cobaltocenium $\mathbf{5}$ described on Scheme 1 were actually the first examples of helical molecular tweezers.

\section{A. 2. Organometallic alkynyl- and vinyl- helicenes}

Aromatics grafted with appropriate metal centers such as $\mathrm{Fe}(\mathrm{II})$ and $\mathrm{Ru}(\mathrm{II})$ through a bridging $\pi$-system (alkynyl, vinyl, aryl) are known to exhibit efficient electronic metal-ligand interaction and interesting electronic and optical properties. ${ }^{22,35}$ In 2012, our group prepared a carbo[6] helicene bearing one or two vinyl-ruthenium moieties. ${ }^{36}$ These enantiopure helical organometallic species $M$-(-)- and $P-(+)-24 a, b$ (Scheme 5) were readily prepared by simple hydroruthenation of enantiopure mono- and bis-2-ethynyl-carbo[6]helicenes $M$-(-)- and $P-(+)-$ 23a,b and displayed several interesting and innovative features. First of all, it was observed that the MR values are doubled upon grafting of the organometallic moiety $\left(P-\mathbf{2 3 a}:[\alpha]_{D}^{23}=\right.$ +3133, $[\phi]_{D}^{23}=+11030\left(\mathrm{CH}_{2} \mathrm{Cl}_{2}, C 510^{-5} \mathrm{M}\right), P-24 \mathbf{a}:[\alpha]_{D}^{23}=$ $+2850,[\phi]_{D}^{23}=+23770\left(\mathrm{CH}_{2} \mathrm{Cl}_{2}, C 510^{-5} \mathrm{M}\right){ }^{*}$ Similarly, the CD spectra are significantly modified with the appearance of new bands at longer wavelengths in $\mathbf{2 4 a}, \mathbf{b}$ compared to $\mathbf{2 3 a}, \mathbf{b}$ due to extended $\pi$-conjugation along the Ru-vinyl-helicene backbone. This efficient interaction between the metal center and the $\pi$ helical core is clearly seen in the molecular orbitals, such as in the HOMO of $\mathbf{2 4 a}, \mathbf{b}$, and makes the vinyl-helicene behave as a non-innocent ligand. ${ }^{36}$ As a consequence, upon oxidation of $M$ or $P$-24a to $M$ - or $P$-[24a $]^{\bullet+}$, the chiroptical properties are greatly modified (Figure 6). Furthermore, the reversibility of the oxidation/reduction process and the possibility to read-out the ECD response enabled us to conceive a helicene-based redox-triggered chiroptical switch. ${ }^{36}$ Also interesting is the fact that the two $\mathrm{Ru}$ centers are not independent in $\mathbf{2 4 b}$ since stepwise mono- and bis-oxidation was observed (two oxidation waves separated by $130 \mathrm{mV}$ ). Note that in $\mathbf{2 4 a}, \mathbf{b}$ the Ru are not stereogenic centers.
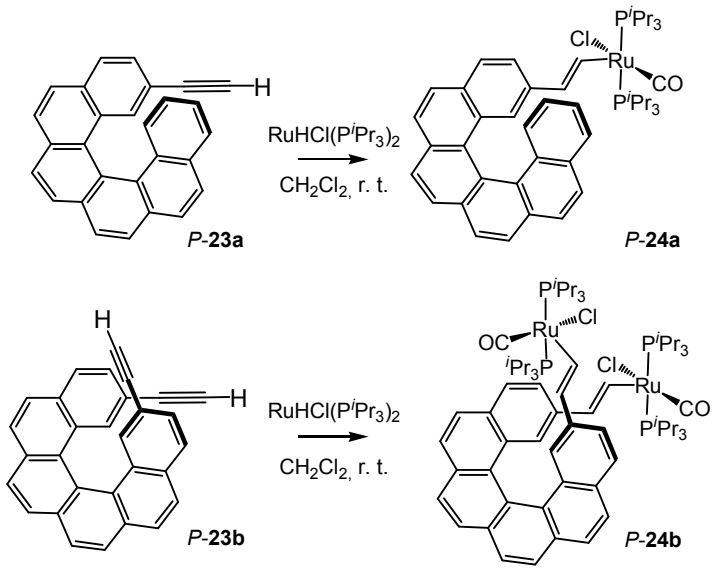

Scheme 5. Synthesis of enantiopure mono- and bis-Ru"-vinyl-helicene complexes $\mathbf{2 4 a , b}$ by hydroruthenation of mono- and bis-ethynyl-helicene proligands 23a,b. ${ }^{36}$

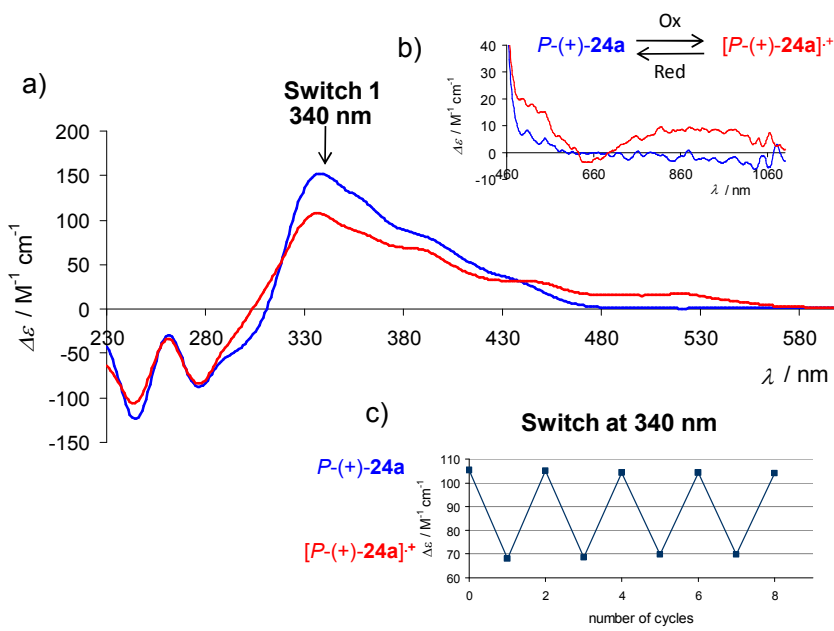

Figure 6. Complex 24a behaving as a helicene-based redox-triggered ECD switch. a) ECD spectra of $P-(+)-24 a$ (blue) and of their oxidized species $P-(+)-[24 a]^{*+}($ red). in dichloroethane at r.t.. b) NIR-CD region spectra of $P-(+)-24 a$ (blue) and $P-(+)-$ ${ }^{[24 a]^{\circ+}}$ (red). c) Redox chiroptical switching $P-(+)-24 a<->[P-(+) 24 a]^{\circ+}$ observed by CD spectroscopy at $340 \mathrm{~nm}^{36}$

More recently, enantiopure vinyl-osmium-helicene complexes $M-(-)$ - and $P-(+)-25$ (Scheme 6) were prepared by hydro-osmylation of enantiopure $M-(-)-$ and $P-(+)-23 \mathbf{a}^{37}$ and enabled access to carbene-osmium-helicene $M-(-)-$ and $P-(+)-$ 26 by using $\mathrm{HCl}$. In these unprecedented helicenic osmiumcarbenes the electronic interaction between the organometallic moiety and the helicene core was broken, which modified the MR values and ECD intensities. Interestingly, we were able to perform the reverse $\mathbf{2 6} \rightarrow \mathbf{2 5}$ transformation with $\mathrm{NEt}_{3}$, potentially leading to a helicene-based acid-base chiroptical switch. This example illustrates the inspiration from simple and well-known organometallic chemistry for the design of new kinds of helicene-based molecular switching systems.

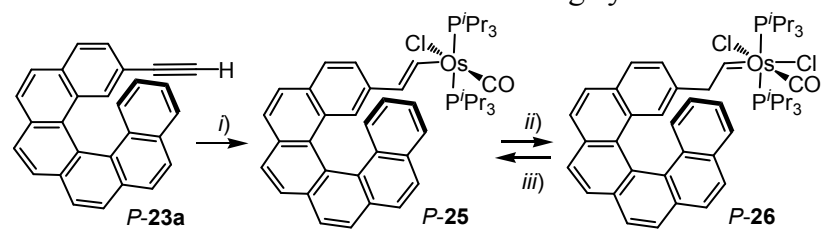

Scheme 6. Synthesis of enantiopure helicene-grafted vinyl-osmium complex $P$-25 and osmium-carbene $P$-26 from enantiopure $P$-23a. i) $\mathrm{HOs}(\mathrm{CO}) \mathrm{Cl}\left(\mathrm{P}^{i} \mathrm{Pr}_{3}\right)_{2}, \mathrm{CH}_{2} \mathrm{Cl}_{2}$, r.t., $\mathrm{Ar}, 3$ days. ii) $\mathrm{HCl}$, toluene. iii) $\mathrm{NEt}_{3}, \mathrm{CH}_{2} \mathrm{Cl}_{2}$.

In 2012, Licandro and coworkers reported the synthesis of racemic tetrathia[7]helicene-based complexes substituted with either a ferrocene (27a-e, Figure 7$)$ or a $\left(\eta^{5}\right.$-cyclohexadienyl)tricarbonylmanganese $(\mathbf{2 8 a}, \mathbf{b}){ }^{38}$ The effective conjugation of the ferrocene moieties with the helicene system through the alkynyl bridges was ascertained by electrochemical and spectroscopic studies. For example, a systematic bathochromic 
shift of the $\pi-\pi^{*}$ transitions was observed in the UV-vis spectra of the complexes as compared with their corresponding proligands. Furthermore, the reversible oxidation wave corresponding to the Fc couple in $27 \mathbf{a}-\mathbf{c}$ was found to be shifted to more positive values, meaning that the Fc moiety was more difficult to oxidize when conjugated with the ethynylthiahelicene moiety. Interestingly, an electroactive conductive film, probably constituted of dimers of $\mathbf{2 7 a}$, could be prepared on a glassy carbon electrode, upon several cyclings around the first oxidation peak. ${ }^{38}$ Note that no electronic communication between the two Fc moieties was observed in $\mathbf{2 7} \mathbf{b}$.
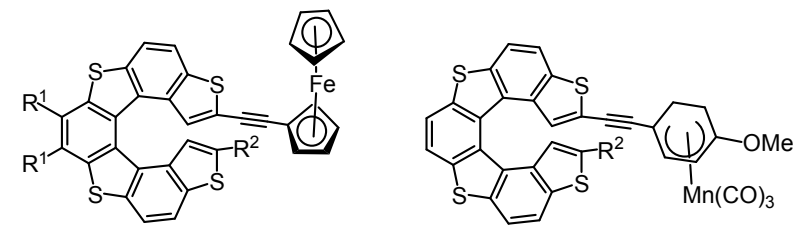

27a: $R^{1}=H, R^{2}=H$

27b: $R^{1}=H, R^{2}=C C-F c$

27c: $\mathrm{R}^{1}=n-\operatorname{Pr}, \mathrm{R}^{2}=\mathrm{H}$

28a: $R^{2}=H$

28b: $R^{2}=C C-[M n]$

27d: $\mathrm{R}^{1}=n-\mathrm{Pr}, \mathrm{R}^{2}=\mathrm{CC}-\mathrm{FC}$

27e: $R^{1}=\mathrm{H}, \mathrm{R}^{2}=\mathrm{C}=\mathrm{N}-\mathrm{SO}_{2} \mathrm{Ph}$

Figure 7. Racemic tetratha[7]helicene-based complexes prepared by Licandro et al. ${ }^{38}$

\section{A.3. Cyclometallated helicenes}

Up to now, the synthesis and properties of heterohelicenes, i.e. helicenes bearing heteroatoms, have been thorougly studied. ${ }^{1,2,5-12}$ In 2010, our group prepared the first class of organometallic helicenes incorporating a metallic ion within their helical backbone. Indeed, inspired by the cyclometalation reaction of phenyl-pyridine derivatives, ${ }^{39}$ we developed a short and efficient strategy to prepare cyclometalated helicene derivatives, named metallahelicenes, by an ortho-metalation reaction of a phenyl-pyridine bearing an extended ortho-fused polycyclic $\pi$-system (Scheme 7).

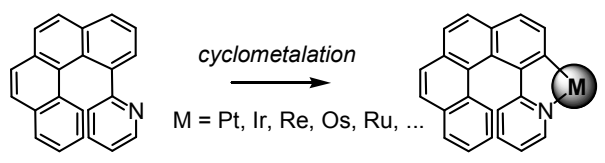

Scheme 7. General synthesis of metallahelicenes by orthometalation reaction.

\section{A.2.1. Platinahelicenes}

The ortho-metalation reaction of 4-(2-pyridyl)benzo[ $g]$ phenanthrene ligands $\mathbf{2 9 a - c ^ { 4 0 , 4 1 }}$ using $\mathrm{K}_{2} \mathrm{PtCl}_{4}$ at high temperature yielded the $\mu$-chloro-bridged complexes 30a-c bearing two $\mathrm{C}^{\wedge} \mathrm{N}$ chelate ligands, which were then transformed under classical conditions to acetylacetonato-capped platina[6]helicene complexes 31a-c (Scheme 8). This efficient strategy consisting of adding two ortho-fused rings in the helical backbone enabled to prepare in half-gram scale the first racemic platina(II)-[6]helicenes bearing different subtituents (OMe, F, H) and was applied to the preparation of diastereomeric $\mathrm{Pt}[6]$ helicene bearing a pinene moiety (31d) and a longer Pt-[7]helicene (31e). X-ray crystallography of complex 31a (see Scheme 9) enabled to identify it as a structural analogue of carbo[6]helicene with for example similar helicities (as defined as the dihedral angle between the two terminal rings). ${ }^{40}$ The stable, soluble, and neutral complexes 31a-e were readily obtained as enantiopure samples by HPLC separations over chiral stationary phases. Later on, enantiopure cycloplatinated helicenes bearing a sulfoxide ligand, either dmso (32a) or enantiopure methyl-p-tolyl-sulfoxide (32f,g) were respectively prepared by direct cycloplatination of proligands 29a,f,g in refluxing toluene and under basic conditions. Enantiopure Pt-[6]helicene 32a was obtained by chiral HPLC. More interestingly, Pt-[8]helicene 32f was obtained from 1-pyridyl-[6]helicene proligand $( \pm)$-29f in enantiomerically and diastereomerically pure forms by using preferential crystallization of diastereomer $\left(M, R_{\mathrm{S}}\right)$-32f over $\left(P, R_{\mathrm{S}}\right)$-32f combined with column chromatography. Similarly, diastereomeric $\left(P, R_{\mathrm{S}}, R_{\mathrm{S}}\right)-\mathbf{3 2 g}$ and $\left(M, R_{\mathrm{S}}, R_{\mathrm{S}}\right)$-32g consisting of bis-platina[6]helicenes were prepared from 1,3-bipridylnaphtalene $29 \mathrm{~g}$ and obtained as pure diastereomers by taking advantage of their different solubilities in different solvents. ${ }^{42}$ Finally, by subsequently replacing the dmso or chiral sulfoxide by an acac ligand, enantiomeric $M-(-)$ and $P-(+)$ pairs of 31a,f,g were obtained (Scheme 9).

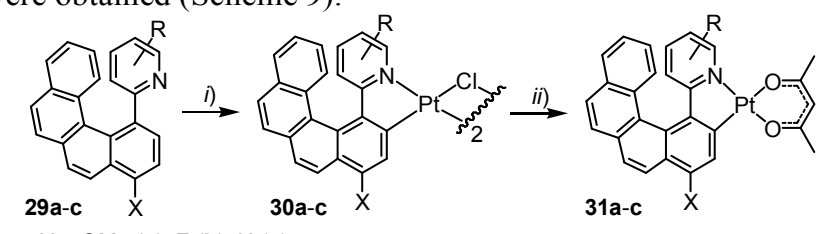

$\mathrm{X}=\mathrm{OMe}(\mathbf{a}), \mathrm{F}(\mathbf{b}), \mathrm{H}(\mathbf{c})$
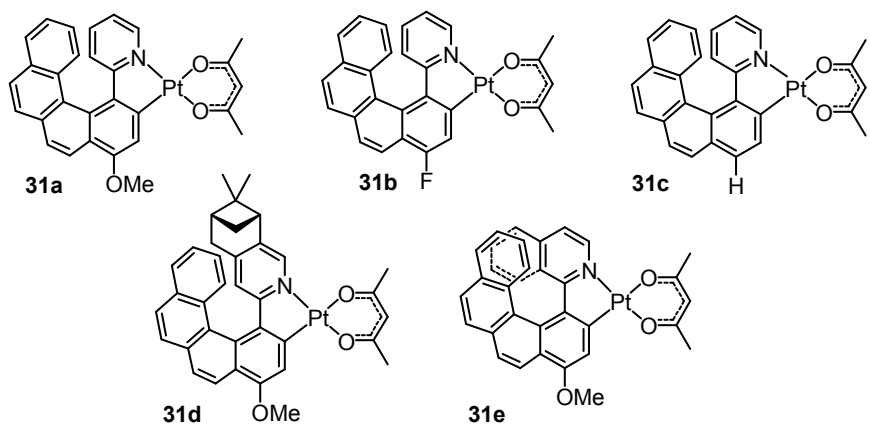

Scheme 8. General synthesis of metallahelicenes 31a-e by orthometalation reaction. Different mono-platinahelicenes prepared using this metodology. i) $\mathrm{K}_{2} \mathrm{PtCl}_{4}$, ethoxyethanol, $\mathrm{H}_{2} \mathrm{O}$, reflux, $16 \mathrm{hrs}$; ii) pentane-2,4-dione, $\mathrm{Na}_{2} \mathrm{CO}_{3}$, ethoxyethanol, reflux, $2 \mathrm{hrs}^{40,41}$ 


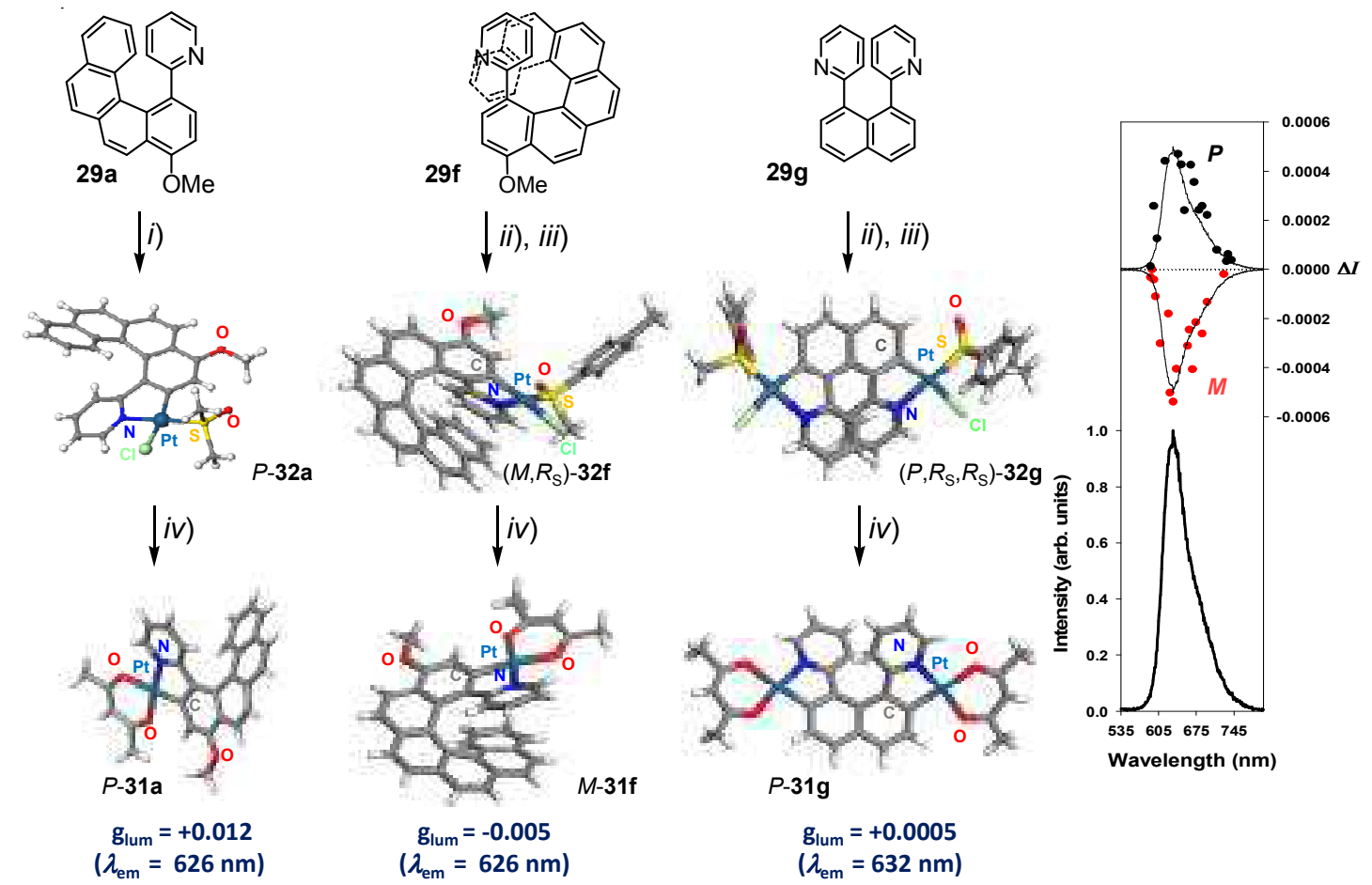

Scheme 9. Left: synthesis of enantiopure and CPL-active phosphorescent platinahelicenes 31a,g,f. $i) \mathrm{PtCl}_{2}\left(\mathrm{dmso}_{2}\right.$, toluene, $\mathrm{Na}_{2} \mathrm{CO}_{3}, \mathrm{Ar}$, reflux, overnight, resolution by chiral HPLC; ii) $\left(R_{\mathrm{S}}, R_{\mathrm{S}}\right)-\mathrm{PtCl}_{2}(p \text {-tolyl-MeSO })_{2}$, toluene, $\mathrm{Na}_{2} \mathrm{CO}_{3}, \mathrm{Ar}$, reflux, overnight; iii) column chromatography and/or crystallization; iv) pentane-2,4-dione, toluene, $\mathrm{Na}_{2} \mathrm{CO}_{3}, \mathrm{Ar}$, reflux, 2 hrs. X-ray crystallographic structures of $\mathbf{3 1 a}, \mathbf{f}, \mathbf{g}$ and $\mathbf{3 2} \mathbf{a}, \mathbf{f}, \mathbf{g}$ (one enantiomer shown). Right: linear luminescence and $\mathrm{CPL}$ signals of $P-(+)$ and $M-(-$ -31g. ${ }^{40-42}$

The diversity of platinahelicenes prepared with different sizes enabled us to study and compare their photophysical (UVvis and luminescence spectra), and chiroptical properties (ECD spectra, MR values, and CPL activity). For example, the UVvisible spectrum of compounds 31a displayed in Figure 8 shows several intense absorption bands below $410 \mathrm{~nm}$ that appeared red-shifted compared to those of its corresponding proligand 29a due to an elongation of the $\pi$-conjugated system via the orthometalation ring closure. In addition, two weak lower-energy broad bands (>450 $\mathrm{nm}$ ) arising from interactions between the metal and the $\pi$-ligands were observed. ${ }^{41}$ The same low-energy tail was present for $\mathrm{Pt}^{\mathrm{II}}$-[8] helicene 31 and $\mathrm{Pt}_{2}{ }^{\mathrm{II}}$ [6]helicene 31g. ${ }^{42}$ The ECD spectra of the organic 2-pyridyl[6]helicene 29f and organometallic Pt-[6]helicene 31a displayed similar overall shape (Figure 8) but with a blueshifted high-energy band for 31a compared to 29f; Pt[8] helicene 31f displayed a stronger and more red-shifted ECD spectrum compared to Pt-[6]helicene 31a, a well-known tendency for helicenes that can be attributed to an enlargement of the $\pi$-electron system; $\mathrm{Pt}_{2}-[6]$ helicene $\mathbf{3 1 g}$ displayed a significantly different $C D$ spectrum from 31a,f and 29f, because of cancellation effects of $\mathrm{CD}$-active transitions with opposite sign rotatory strengths and similar energies, as indicated by TDDFT calculations. ${ }^{42}$

Interactions between the platinum center and the $\pi$-ligands are responsible for strong phosphorescence at room temperature, thanks to efficient spin-orbit coupling. ${ }^{39}$ Indeed, platinahelicenes 31a-c,e and 31f,g are efficient deep-red phosphors, with emission maxima between 630-700 nm, quantum yields around $5 \%$ in deoxygenated solution at room temperature (Table 2) and luminescence lifetimes of 10-20 $\mu \mathrm{s}$. Interestingly, platinahelicenes $\mathbf{3 1 a , f , g}$ displayed circularly polarized luminescence with dissymmetry factors ( $\mathrm{g}_{\text {lum }}$ values) as high as $10^{-2}$, which corresponded to one order of magnitude bigger than for usual organic helicenes. ${ }^{1}$ The $\mathrm{g}_{\text {lum }}$ values appeared positive for the $P$ enantiomers and negative for the $M$, which seems to not always be the case. ${ }^{43}$ 

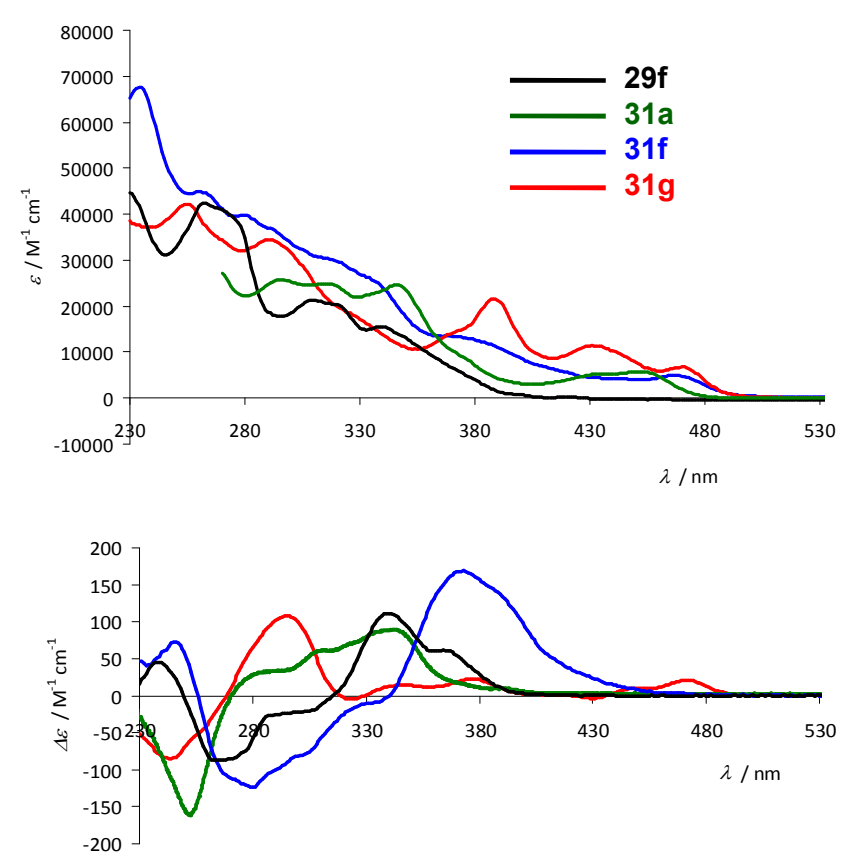

Figure 8. Comparison of the experimental UV-vis (top) and ECD spectra (bottom) of $P$-29f (black line), $P$-31f (blue line), $P$-31g (red line), and $P$-31a (green line). ${ }^{42}$

Table 2. Photophysical data of platinahelicene complexes 31a-c,f,g., ${ }^{\text {a, } 40,42}$

\begin{tabular}{cccccc}
\hline & 31a & 31b & 31c & 31f & 31g \\
\hline $\begin{array}{c}\text { Emission } \\
\lambda_{\max } / \mathrm{nm}\end{array}$ & 644 & 640 & 642 & 648 & 633,673 \\
$(298 \mathrm{~K})$ & & & & & \\
$\Phi_{\mathrm{f}} \times 10^{2}$ & 10 & 6.9 & 6.5 & 5.6 & 13 \\
$(298 \mathrm{~K})$ & & 12 & 11 & 16.5 & 18.7 \\
$\tau_{\text {lum }} / \mathrm{ms}$ & 21 & & & & \\
$(298 \mathrm{~K})$ & & & & &
\end{tabular}

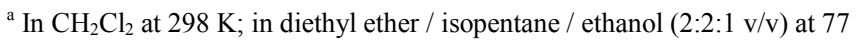
$\mathrm{K}$.

The platinahelicene chemistry demonstrates how powerful organometallic chemistry can be to generate new helical structures with interesting non polarized and circularly polarized luminescence properties. An additional advantage is the redox activity of the metallic ion. Indeed, the $\mathrm{Pt}^{\mathrm{II}}$ center in $P$-31 a could be readily oxidized to a $\mathrm{Pt}^{\mathrm{IV}}$ by reaction with iodine, thus giving new enantiopure $\mathrm{Pt}^{\mathrm{IV}}-[6]$ helicene $P$-33a with chiroptical properties that were different from $P$-31a and with the luminescence switched off (Scheme 10a). ${ }^{41}$ Complex $P$-33a could be reduced back to $P$-31a with zinc powder. Another important aspect in the chemistry of metallated helicenes is the use of coordination chemistry to assemble several helicene moieties within the same molecular architecture, as demonstrated in the bis- $\left(\mathrm{Pt}^{\mathrm{III}}\right.$-helicene $)$

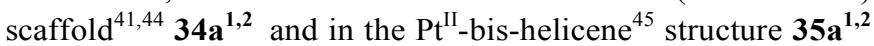
(Scheme 10b). It is worth noting that such assemblies of helicenes are impossible to prepare by using organic chemical processes. These organometallic assemblies displayed several interesting and innovative features.

a)

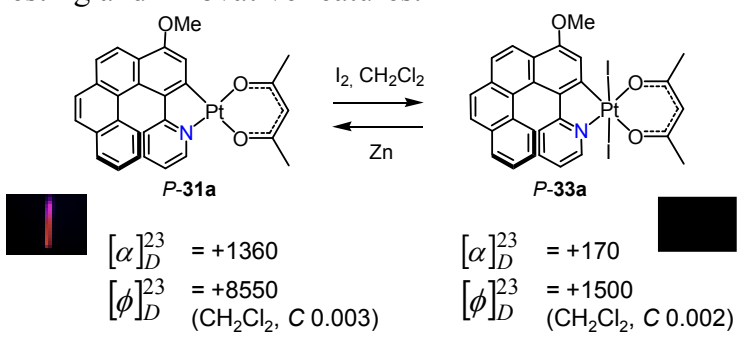

b)

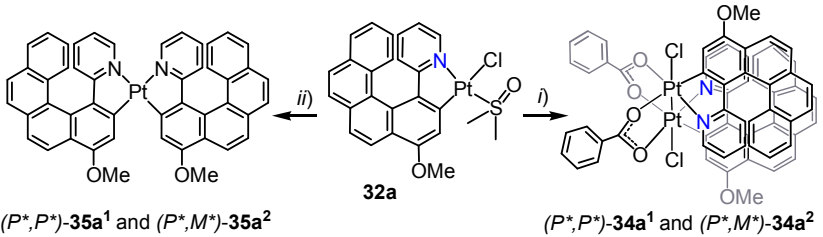

Scheme 10. a) Oxidation of $\mathrm{Pt}$-[6]helicene 31a to $P t^{\mathrm{IV}}-[6]$ helicene 33a and reverse reduction process accompanied with modification of the emission and optical rotation. b) Synthesis of homochiral and heterochiral bis-( $\mathrm{Pt}^{\mathrm{III}}[6]$ helicene) $\left(34 \mathrm{a}^{\mathbf{1 , 2}}\right)^{41,44}$ and $\mathrm{Pt}$-bis-([6]helicene) $\left(35 \mathrm{a}^{\mathbf{1 , 2}}\right)^{45}$ assemblies; i) $\mathrm{PhCO}_{2} \mathrm{Ag}, \mathrm{CHCl}_{3} / \mathrm{THF}$, rt, $12 \mathrm{hrs}$, Ar; ii) $\mathrm{AgBF}_{4}$, acetone then $\mathrm{Na}_{2} \mathrm{CO}_{3}$, toluene, reflux, $10 \mathrm{~min}$, $\mathrm{Ar}$.

As illustrated on Scheme $11 \mathrm{a}$, an isomerization process from heterochiral $(M, P)-\mathbf{3 4} \mathbf{a}^{2}$ to the more stable homochiral $\left(P^{*}, P^{*}\right)-\mathbf{3 4 a ^ { 1 }}$ occured when refluxing in toluene for several days, certainly due to high steric congestion around the $\mathrm{Pt}^{\mathrm{III}}-\mathrm{Pt}^{\mathrm{III}}$ scaffold. In addition, enantiopure $(P, P)-(+)$ and $(M, M)-(-)-\mathbf{3 4} \mathbf{a}^{\mathbf{1}}$ complexes were prepared from enantiopure samples of 32a and revealed highly intense circular dichroism spectra and huge optical rotations $\left(P-\mathbf{3 2 a}:[\alpha]_{D}^{23}=+1100,[\phi]_{D}^{23}=+7060\left(\mathrm{CH}_{2} \mathrm{Cl}_{2}\right.\right.$, $C$ 0.01); $(P, P)-\mathbf{3 4 a}^{\mathbf{1}}:[\alpha]_{D}^{23}=+2060,[\phi]_{D}^{23}=+28200\left(\mathrm{CH}_{2} \mathrm{Cl}_{2}, C\right.$ $0.04))$. ${ }^{*}$ Such an increase was interpreted as the consequence of efficient conjugation between the two helical $\pi$-ligands through the Pt-Pt bond ( $\sigma-\pi$ conjugation). ${ }^{41,44}$ Concerning the synthesis of $35 \mathbf{a}^{1,2}$, the $\mathrm{C}-\mathrm{H}$ activation process of the second cycloplatination step combined with a similar heterochiral to homochiral dynamic isomerization globally resulted in an unprecedented diastereoselective/enantioselective process. ${ }^{45}$ Note that $\mathrm{Pt}^{\mathrm{II}}$-bis-helicene assemblies $\mathbf{3 5} \mathbf{a}^{\mathbf{1}, \mathbf{2}}$ displayed the same structural features as $\mathrm{Pt}^{\mathrm{II}}$-(ppy) $)_{2}$ complexes (ppy:2-phenylpyridinato) described by von Zelewsky et al., ${ }^{46}$ in which two ppy-type are arranged in mutual cis position (trans effect, Scheme $11 \mathrm{~b}$ ), and with either a bow-shaped geometry or a $\Delta / \Lambda$ stereochemistry around the Pt center (Scheme 11c). 

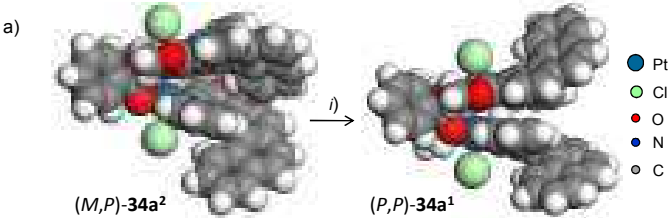

b)

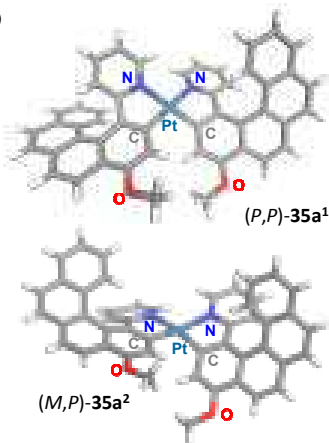

c)

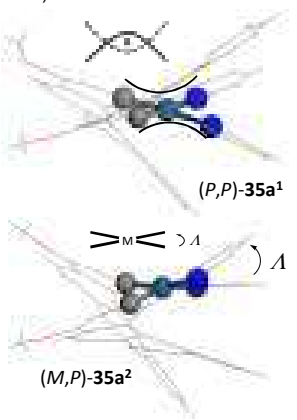

Scheme 11. a) Isomerization of heterochiral $(M, P)-\mathbf{3 4} \mathbf{a}^{\mathbf{2}}$ to homochiral $(P, P)-\mathbf{3 4} \mathbf{a}^{\mathbf{1}}$ Pt"'-Pt'"I scaffolds; ${ }^{41,44}$ i) toluene, reflux, 3 days. b) X-ray crystallographic structures of homochiral $(P, P)-35 a^{1}$ and heterochiral $\left.(M, P)-35 a^{2}{ }^{45} \mathrm{c}\right)$ Bowlike and $\Lambda$ geometries around the $\mathrm{Pt}$ " center in $\mathbf{3 5} \mathrm{a}^{\mathbf{1}}$ and $\mathbf{3 5} \mathrm{a}^{2}$ respectively.

\section{A.2.2. Osma- and irida-helicenes}

It can be seen from the previous paragraph that the cycloplatination of $\pi$-helical ligands leads to a rich variety of platinahelicenes with different structures, redox states, and uncommon assemblies. This synthetic strategy was applied to other metallic centers such as $\mathrm{Ir}^{\mathrm{III}}$ or $\mathrm{Os}^{\mathrm{IV}}$, thus leading to irida[6] helicenes ${ }^{40} \mathbf{3 6 a}$ and $\mathbf{3 6} \mathbf{b}$ with either two or four helicenes ligands surrounding one or two Ir centers respectively and to osmahelicene $37 .{ }^{47}$ Similar organometallic helicenes bearing other metallic centers such as $\operatorname{Ru}(\mathrm{II})$ or $\operatorname{Re}(\mathrm{I})$ are currently under investigation in our group.

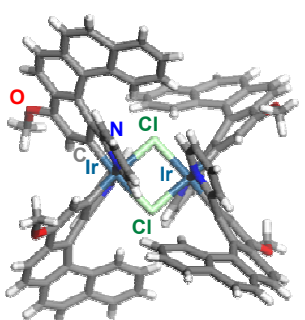

$36 \mathrm{a}$

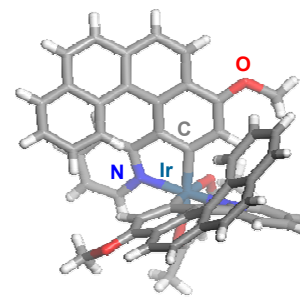

$36 \mathrm{~b}$

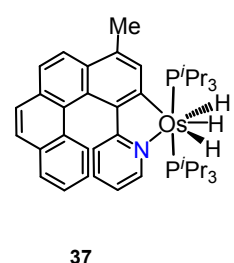

37
Figure 9. X-ray crystallographic structures of homochiral $(P, P, P, P)-\left[\mathrm{Ir}^{\prime \prime \prime}-\mu-\mathrm{Cl}-(31 \mathrm{a}-\right.$ $\mathrm{H})]_{2}(36 \mathrm{a})$ and $(P, P)-\mathrm{Ir}^{\mathrm{III}}-(31 \mathrm{a}-\mathrm{H})_{2}(36 \mathbf{b}) .^{40}$ Chemical structure of Os ${ }^{\mathrm{IV}}-[6]$ helicene 37. ${ }^{47}$

\section{B Coordination of helicenic ligands}

Metals are powerful templates for assembling $\pi$-conjugated ligands with coordinating heteroatoms into well-defined molecular structures. ${ }^{48,49}$ This approach involves a careful design of a helical $\pi$-conjugated ligand with appropriate coordination functionalities guided by the basic concepts of coordination chemistry (trans-effect, hemilability...). It enables the construction of original chiral architectures that are difficult to achieve by regular organic chemistry. This strategy is also fruitful for the development of new catalytic systems for asymmetric synthesis and innovative molecular materials with targeted properties furnished by the type of metal and ligand chosen.

\section{B. 1. Helicenic ligands for asymmetric transition metal catalysis}

The most widely used ligands in asymmetric transition metal catalysis are chiral phosphanes. The first helicenic phosphane ligands ${ }^{50}$ such as 2,15-bis(diphenylphosphino)hexahelicene 38, also named Heliphos or more often PHel (Figure 10), were prepared by Brunner et al. in $1997 . .^{51}$ The same year, enantiopure samples of PHel were obtained by Reetz et al. ${ }^{52}$ by using chiral HPLC and tested in the rhodium catalyzed asymmetric hydrogenation of di-methyl itaconic acid ester. A $39 \%$ ee was obtained in this pioneering example of asymmetric catalysis using a helicene-based complex. Note that the intramolecular P-P distance (6.48 ̊) obtained from the Xray crystallographic structure is too large for PHel to act as a ditopic chelating ligand and suggests that it rather behaved as a monodentate one. In 2000, the same enantiopure ligand was used in a palladium catalyzed kinetic resolution involving allylic substitution, with ee's up to $99 \%$ for the starting material. ${ }^{53}$ In 2000, Katz et al. successfully used a bis[5]helicenediol ([5]HELOL, $(M, M, S)$-39, Figure 10) in the asymmetric addition of diethylzinc to aromatic aldehydes with $e e^{\prime}$ s up to $81 \% .{ }^{54}$ Note that the [5]HELOL ligand mixes helical and axial chirality. Furthermore, the metal center placed in the central groove of the ligand probably helps with the efficiency of the asymmetric catalysis. A pre-transition state involving the coordination of zinc was proposed by the authors for rationalizing the approach of the aldehyde. Two years later it was shown by Yamagushi et al. that similar enantioselective addition of $\mathrm{Et}_{2} \mathrm{Zn}$ to aromatic aldehydes was catalyzed with moderate $e e^{\prime}$ s by a macrocyclic amide bearing two helical 1,12dimethylbenzo[c]phenanthrene-5,8-dicarboxylates. ${ }^{55}$ In 2003, the same group prepared phosphites displaying helical, axial, and central chirality, such as $(M, M, S, 1 R, 2 S, 5 R)-\mathbf{4 0}$, as effective ligands for the rhodium-catalyzed enantioselective hydrogenation of di-Me itaconate with ee's up to $96 \%$. It was shown that the stereochemistry of the helicene moiety plays an important role in the asymmetric induction, and matched/mismatched phenomena were observed between helical and axial chirality. ${ }^{56}$ In 2011, Stary et al. used chiral ligands such as $(P, S)-(+)-\mathbf{4 1}$ bearing a pendant phosphite moiety either in asymmetric Rh-catalyzed hydroformylations (moderate $e e^{\prime}$ s up to $32 \%$ ) or in Ir-catalyzed allylic amination reactions (high $e e^{\prime}$ s up to $94 \%$ ). ${ }^{57}$ Very recently, Marinetti et al. prepared phosphahelicenes structures as efficient platforms for asymmetric gold catalysis (in cycloisomerizations of $\mathrm{N}$-tethered 1,6-enynes and dienynes). ${ }^{58}$ Fine-tuning of these phosphahelicene ligands furnished efficient catalytic systems such as $\left(S_{\mathrm{P}}, P\right)$-endo-42 displaying high activity and giving high $e e^{\prime} s$. In $\left(S_{\mathrm{P}}, P\right)$-endo-42, the $\mathrm{P}$ atom is embedded within the 
helical structure and the gold atom points towards the helical groove (see model in Figure 10). Iridium-phosphahelicene complexes of have also been prepared and may also show good catalytic efficiency in the future. ${ }^{59}$ Note that other goldcatalyzed cycloisomerizations, i.e. intramolecular allene hydroarylation, were also performed recently by Hashmi, Licandro et al. using tetrathiahelicene phosphane ligands (such as in Thiaheliphos complex 43) but in racemic series. ${ }^{60}$ The same Thiaheliphos ligand was used in enantiopure form in the rhodium catalyzed hydrogenation of itaconic acid ester and 2acetamidoacrylate, giving final products with $e e^{\text {'s }}$ up to $40 \% .{ }^{61}$ Finally, in all the former cases the ligands possess either $\mathrm{P}$ or $\mathrm{O}$ heteroatoms that enable coordination to the transition-metal center for enantioselective catalysis. It is however worth mentioning that helical ligands without coordinating heteroatoms, i.e. carbo[6]helicene and a thia[7]helicene have proven efficient in the autocatalytic process based on addition of diisopropylzinc to pyrimidine-5-carbaldehyde (Soai reaction). ${ }^{62,63}$

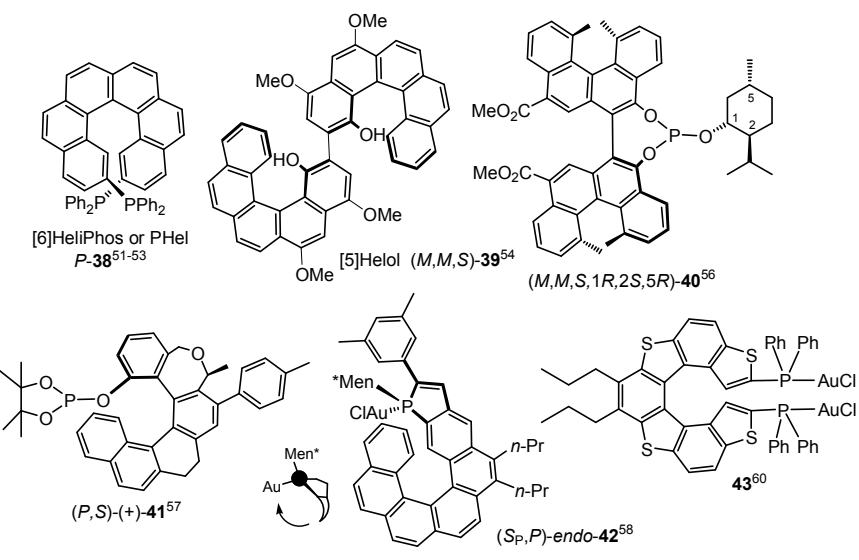

Figure 10. Helical ligands used in transition metal asymmetric catalysis.

Note that in 2007 Ben Hassine, Marinetti, et al. synthesized racemic 2-(diphenylphosphino)heptahelicene 44 and prepared its ruthenium complex of $\mathrm{Ru}(\mathbf{4 4}) \mathrm{Cl}_{2}$ cymene. More importantly, the enantiomeric resolution of $\mathbf{4 4}$ was performed by reaction with enantiopure ortho-metallated bis- $[R-1$ (naphthyl)ethylamine- $\left.C^{2}, N\right]$-di- $\mu$-chloro-dipalladium complex followed by chromatographic separation of the resulting diastereomeric complexes $(P, R)-\mathbf{4 5 a}$ and $(M, R)$-45b (Scheme 12). This is a nice use of coordination chemistry to enantiomerically resolve a helicene bearing a coordinating unit. ${ }^{64}$ In 2009, 3-diphenylphosphino-hexahelicene and its $\mathrm{Ru}(\mathrm{II})$ and $\mathrm{Pd}(\mathrm{II})$ complexes were prepared by Ben Hassine et al. but in racemic forms. ${ }^{65}$ To our knowledge these complexes have not been tested in catalysis.

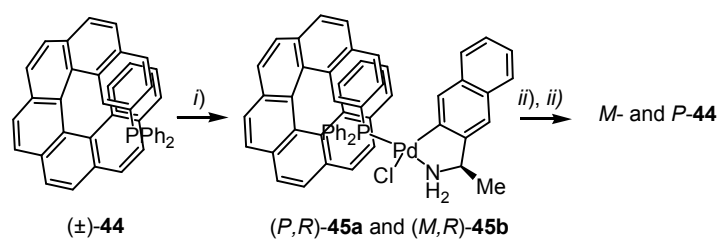

Scheme 12. Enantiomeric resolution of helicene-phosphane ligand $\mathbf{4 4}$ by preferential crystallization of diatereomeric Pd" complexes $45 \mathbf{a}, \mathbf{b}$. $i)$ bis-[R-1(naphthyl)ethylamine- $\left.C^{2}, N\right]$-di- $\mu$-chloro-dipalladium complex, acetone, r.t.; ii) column chromatography; iii) dppe, $\mathrm{CH}_{2} \mathrm{Cl}_{2}$, r.t.. ${ }^{64}$

\section{B.2. Coordination complexes for molecular materials}

Coordination chemistry offers a simple way to tune the optical and electronic properties of the $\pi$-ligands since both the coordination sphere geometry and the nature of the metalligand interaction can be readily modified by varying the metal center. This will produce a great impact on the properties of the molecule. However the selectivity aspects (kinetics vs. thermodynamics, stereoselectivity, ...) are major issues that need to be controlled.

\section{B.2.1. Coordination of monodentate helicenic ligands}

Compared to carbohelicenes, the thiahelicene series is easier to post-functionalize and can be decorated with groups displaying good coordinating ability, such as cyano ligands. In this context, racemic tetrathia[7]helicene nitrile derivatives were prepared by Licandro, Maiorana et al. and their Ru(II) and $\mathrm{Fe}(\mathrm{II})$ complexes were synthesized. ${ }^{66}$ An interesting isomerization process of the $\mathrm{Ru}(\mathrm{II})$ complex 46 was observed upon slow crystallization (Scheme 13). Such iron and ruthenium complexes were prepared for future NLO studies provided that these complexes are available in enantiopure forms. Note that their UV-vis spectra revealed metal to ligand charge transfer (MLCT) transitions in the low energy domain.

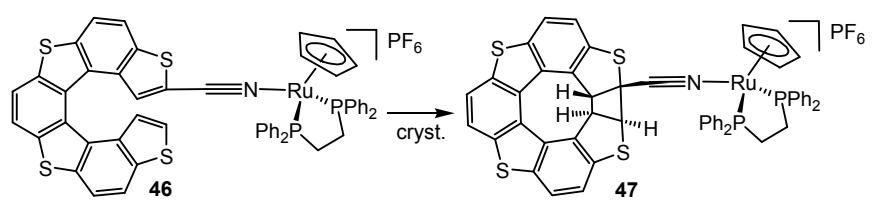

Scheme 13. Tetrathiahelicene-nitrile complex $\mathbf{4 6}$ and isomerization to $\mathbf{4 7}{ }^{66}$

Azahelicene ligands (helicenes bearing one or several nitrogen atoms in their $\pi$-conjugated backbone) have been the focus of great attention since they can be readily prepared by a diversity of methods ${ }^{1,6,11}$ and can be used as chiral organic catalysts $^{50}$ or as molecular materials in optoelectronic devices. ${ }^{67,68}$ Among their intrinsic features are their supramolecular organization in the solid state, ${ }^{68}$ their fluorescence and phosphorescence properties, ${ }^{69}$ and their strong proton affinity depending on the position of the $\mathrm{N}$ atom within the helix. ${ }^{70}$ In 2008, Stary et al. used aza[6]helicenes 48a,b (Figute 11) as $\mathrm{N}$ ligands for coordination, and 1:2 $\mathrm{Ag}^{\mathrm{I}}$ aza[6]helicene complexes such as $\mathbf{4 9}$ were prepared and 
charaterized by X-ray crystallography. Complex 49 exhibited a T-shaped structure with two homochiral aza[6]helicene units coordinated and the silver atom embedded within the $\pi$-electron system. Actually, the coordination environment around the silver atom was best described as a trigonal bipyramid, in which each 1-aza[6] helicene actually binds as an $\eta^{3}-N, C, C$ ligand, with the nitrogen atom and $\mathrm{C}=\mathrm{C}$ bond occupying axial and equatorial positions, respectively. ${ }^{71}$ The same group observed similar preferential formation of homochiral $\mathrm{Ag}^{+}$ complexes in the gas phase. ${ }^{72}$ Indeed, they prepared enantiopure deuterated 1-aza[6]helicene $\left[7,8-\mathrm{D}_{2}\right]-48 \mathrm{a}$ and probed the chiral discrimination in $\mathrm{Ag}^{\mathrm{I}}$-bound dimers of the type $[\mathrm{LAgL}]^{+}\left(\mathrm{L}, \mathrm{L}^{\prime}=\mathbf{4 8 a}\right.$ or $\left.\left[7,8-\mathrm{D}_{2}\right]-\mathbf{4 8 a}\right)$ by electrospray mass spectrometry. A pronounced preference for the formation of homochiral $(P, P)$ and $(M, M)$ dimers over the heterochiral $(M, P)$ was observed. Competitive experiments with mixtures of 1- and 2-aza[6] helicene 48a,b suggested a largely preferred coordination of 1-aza[6] helicene to the silver(I) cation, in agreement with stronger basicity. The distinction between homochiral and heterochiral dimers of 1 -aza[n]helicenes $(n=$ 1,7) with alkaline cations $\left(\mathrm{Li}^{+}, \mathrm{Na}^{+}, \mathrm{K}^{+}\right)$was studied by Alkorta et al. by DFT calculations and was found greater in the case of lithium with $\mathrm{n}=6 .{ }^{73}$ The racemization barriers of the $1: 1$ complexes were also examined and appeared larger in the complexes than in the non-coordinated ligands.

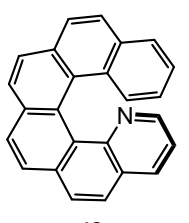

$48 a$

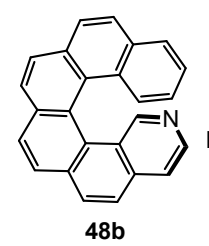

48b

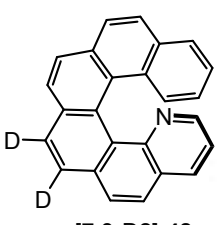

[7,8-D2]-48a

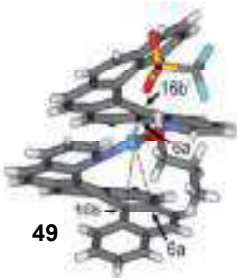

Figure 11. 1 and 2-Azahelicene ligands studied for coordination with AgOTf. X-ra crystallographic structure of $\left(P^{*}, P^{*}\right)$ Ag'-bis-1-aza[6] helicene complex $49 .{ }^{71,72}$ Adapted with permission from ref. 71 .

Very recently, the coordination of an aza[6]helicene to square planar platinum(II) revealed a new aspect of reactivity in chiral transition metal complexes. ${ }^{74}$ Indeed, in collaboration with Mele's group, we have observed that cis $-\mathrm{PtCl}_{2}(\mathrm{NCEt}) \mathrm{PPh}_{3}$ reacted differently with either racemic or enantiopure 4aza[6] helicene 48c giving respectively cis (racemic, 51) and trans (enantiopure, 52) 4-aza[6]helicene-bis-chlorotriphenylphosphine-platinum(II) complexes (Scheme 14). This unexpected reactivity is explained through a dynamic process (crystallization-induced diastereoselective transformation). Indeed, the racemic complex cis-51 readily precipitated in refluxing toluene therefore displacing the cis-50/trans-50' equilibrium while the enantiopure series was soluble in refluxing toluene and yielded the more thermodynamically stable $M$ - or $P$-trans-52. Furthermore, X-ray crystallographic structure of racemic complex cis-51 revealed the appearance of planar chirality around the square planar Pt center whose handedness was imposed by the helicene's one through efficient chiral induction (Scheme 14).
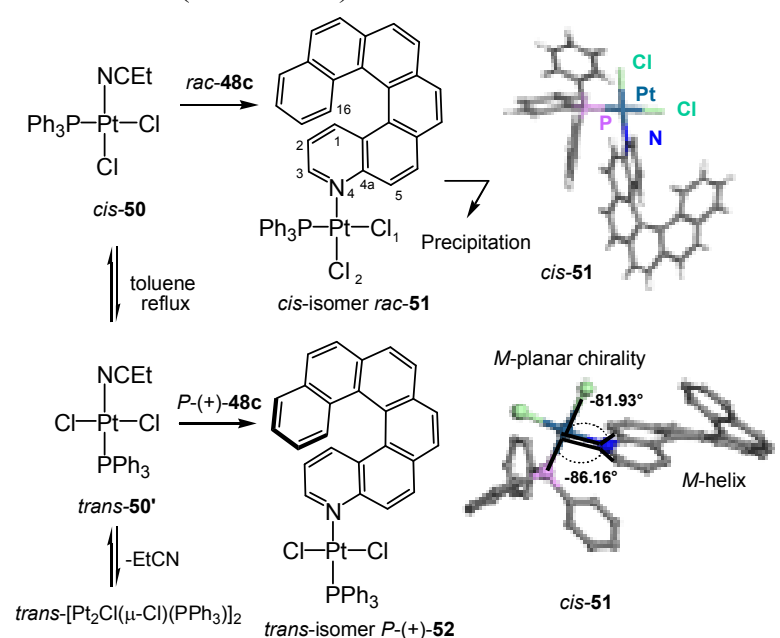

Scheme 14. Different reactivity observed for racemic and enantiopure ligand 48c, yielding respectively cis-51 or trans-52 platinum complexes. X-ray crystallographic structure of cis-51 (one enantiomer shown) and dihedral angles used to define the $M$ planar chirality around the Pt center. ${ }^{74}$

\section{B.2.2. Coordination of extended $\pi$-conjugated helicenic $P, N$ bidentate ligands}

Heteroditopic 2-pyridylphosphole derivatives have been utilized as 1,4-chelating ligands towards transition metals. ${ }^{75,76}$ They possess two coordination centres with different stereoelectronic properties ("hard" nitrogen and "soft" phosphorus centres) which, in accordance with Pearson's antisymbiotic effect (trans effect), can control the orientation of two 1,4-P,N ligands around a square planar $\mathrm{d}^{8}$-metal centre $\left(\mathrm{Pd}^{2+}, \mathrm{Pt}^{2+}\right)$, thus yielding $C_{2}$-symmetrical complexes with optimized optical properties such as second order NLO activity. As a continuity of this work, our group has synthesized aza[4]helicenephosphole 53 that acted as an efficient bidentate 1,4- $P, N$ chelate ligand and yielded stable metal-bis(helicene) complexes 54 and 55 of respective formula $\left[\operatorname{Pd}(\mathbf{5 3})_{2}\right]^{2+}$ and $\left[\mathrm{Cu}(\mathbf{5 3})_{2}\right]^{+}$ (Scheme 15). ${ }^{77}$ Indeed, upon coordination to a square-planar $\mathrm{Pd}(\mathrm{II})$ and a tetrahedral $\mathrm{Cu}(\mathrm{I})$ ions, the metal centers became stereogenic, with respectively distorted square-planar or tetrahedral spiro geometry. Although aza[4]helicene-phosphole 53 have two stereogenic elements (the helix and the $\mathrm{P}$ atom) that are configurationally labile due to low inversion barriers, the obtention of X-ray crystallographic structures of assemblies $\mathbf{5 4}$ and $\mathbf{5 5}$ allowed to examine the stereoselectivity of the $\mathrm{Pd}(\mathrm{II})$ or $\mathrm{Cu}(\mathrm{I})$ coordination of these model molecules (see Scheme 15). Among all the possible stereoisomers that can be formed, $C_{2}$-symmetrical $\mathrm{Pd}^{\mathrm{II}}$-bis(helicene) $\mathbf{5 4}$ was obtained in the solid state as a pair of enantiomers $\left(M, M, S_{\mathrm{P}}, S_{\mathrm{P}}, \Lambda_{\mathrm{Pd}}\right)$ and $\left(P, P, R_{\mathrm{P}}, R_{\mathrm{P}}, \Delta_{\mathrm{Pd}}\right)$ only. Likewise, the $\left(P, M, S_{\mathrm{P}}, S_{\mathrm{P}}, \Lambda_{\mathrm{Cu}}\right)-$ and $\left(M, P, R_{\mathrm{P}}, R_{\mathrm{P}}, \Delta_{\mathrm{Cu}}\right)-\mathbf{5 5} \mathrm{Cu}^{\mathrm{I}}$-bis(helicene) assemblies were obtained. Note that in both cases, the simplicity of the ${ }^{31} \mathrm{P}$ and ${ }^{1} \mathrm{H}$ NMR spectra was also consistent with high stereoselectivity of the coordination process in solution. 
We have then prepared aza[6]helicene-phosphole 56 with enantiopure $P$-helix but as a $\left(P, R_{\mathrm{P}}\right)$ and $\left(P, S_{\mathrm{P}}\right)$ epimeric mixture due to the inversion of the stereochemistry at the phosphorus atom. ${ }^{78}$ Complexation to $\mathrm{Pd}(\mathrm{II})$ and $\mathrm{Cu}(\mathrm{I})$ yielded stable metalbis(helicene) complexes 57 and 58. It was found that $\mathrm{Pd}(\mathrm{II})$ was more efficient than $\mathrm{Cu}(\mathrm{I})$ to stereoselectively organize two aza[6]helicene phosphole ligands around the metallic ion thanks to steric hindrance combined with trans effects and configurational lability at the phosphole's $\mathrm{P}$ atom. Indeed, in complex $(P, P)-\mathbf{5 7}$, the lability enabled the $\mathrm{P}$ atom to adapt its configuration upon coordination in order to minimize the steric congestion induced by the two helical units, while the trans effect resulted in aligning the two P,N chelates in a cis fashion around the $\mathrm{Pd}(\mathrm{II})$ center. Overall, the $P$ handedness of the aza[6] helicene unit was transferred to the $\mathrm{P}$ atom fixed at $R$ stereochemistry which in turn imposed the $\Delta$ configuration to the Pd center. DFT calculations further evidenced that the $\left(P, P, R_{\mathrm{P}}, R_{\mathrm{P}}, \Delta_{\mathrm{Pd}}\right)$ diastereomer was $19.4 \mathrm{kcal} / \mathrm{mol}$ more stable than the $\left(P, P, S_{\mathrm{P}}, S_{\mathrm{P}}, \Delta_{\mathrm{Pd}}\right)$ one (Figure 12) and that the complex having a $\Lambda_{\mathrm{Pd}}$ configuration is not a minimum on the potential energy surface. ${ }^{79}$ On the contrary, theoretical calculations performed on complex $\mathbf{5 8}$ revealed that several diastereoisomers have similar energies (Figure 12) and consequently that the coordination to $\mathrm{Cu}(\mathrm{I})$ was not stereoselective.

Thanks to such a highly controlled stereoselective process, the chiroptical properties of the $\mathrm{Pd}^{\mathrm{II}}$-bis(helicene) assemblies 57 were significantly enhanced as compared to the starting ligand 56 and to the $\mathrm{Cu}^{\mathrm{I}}$-bis(helicene) assembly 58 (see Figure 12). The ECD spectrum observed for $\mathbf{5 6}$ was characteristic of an extended $\pi$-conjugated helical ligand, since most of the strongly ECD-active bands imply electronic transitions from molecular orbitals whose electron density is distributed all over the helicene-phosphole skeleton. In the Pd(II) complex 57, efficient metal-ligand electronic interaction induced MLCT type transitions responsible for the low-energy ECD-active tails (400-500 nm). This was not the case for $\mathrm{Cu}(\mathrm{I})$ complex $\mathbf{5 8}$ because metal-ligand electronic interactions were much weaker and the stereoselectivity very low (vide supra). ${ }^{79}$ In conclusion, in spite of their peculiar structures and the presence of sterically demanding azahelicene substituents, the heteroditopic $P, N$ moieties of derivatives $\mathbf{5 3 , 5 6}$ dictate their coordination behaviour allowing a predictable coordination driven molecular engineering to be performed.

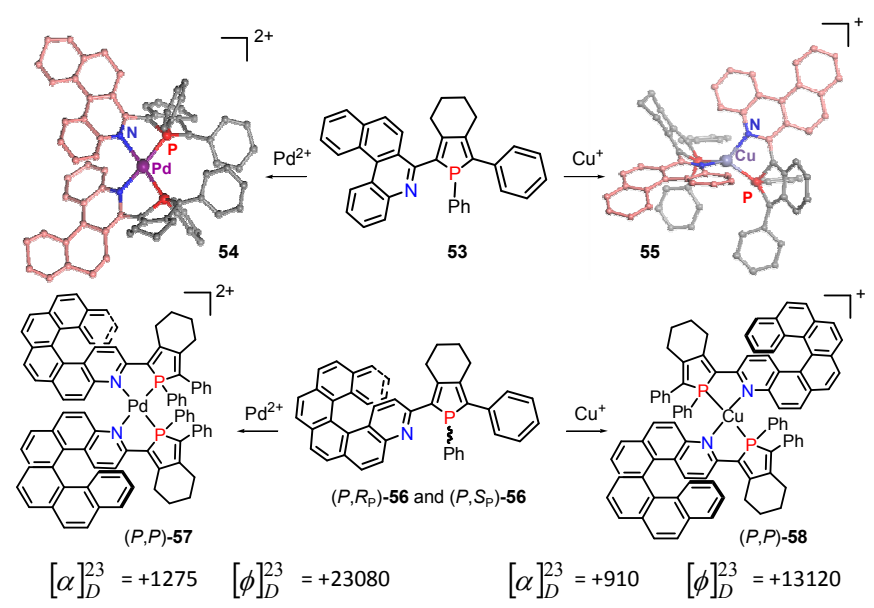

Scheme 15. Stereoselective complexation process of aza[4]- and aza[6]helicenephospholes 53 and 56 acting as 1,4-P,N-chelate ligands to $\mathrm{Pd}(\mathrm{II})$ and $\mathrm{Cu}(\mathrm{I})$ complexes $\mathbf{5 4 , 5 7}$ and $\mathbf{5 5 , 5 8}$. Specific and molar rotations of $\mathbf{5 7 , 5 8}$ are measured in $\mathrm{CH}_{2} \mathrm{Cl}_{2}(\mathrm{C} 0.01-0.02)$. ${ }^{77-79}$

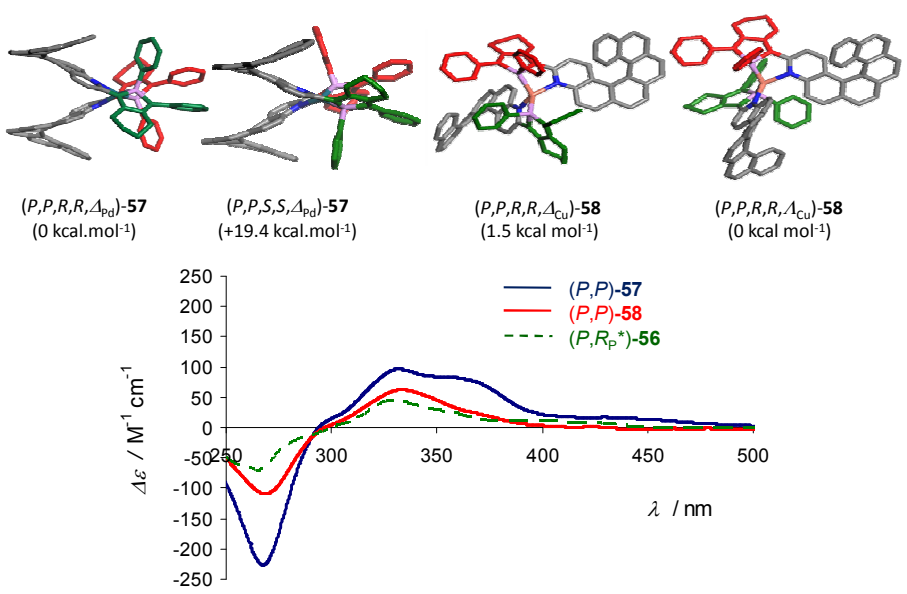

Figure 12. Optimized structures and relative energies for possible diastereoisomeric complexes of $\mathbf{5 7 , 5 8}$ obtained by DFT calculations. CD spectra of compounds 56 (green), 57 (blue) and 58 (red), having P-configuration helices. $^{79}$

\section{B.2.3. Coordination of multitopic helicenic ligands}

We have shown in the former paragraph that phospholemodified azahelicenes are well designed to self-assemble onto metallic ions in a highly stereoselective way, affording original chiral architectures. Along these lines, bis(aza[4helicene)phosphole 59 (Scheme 16) acting as a N,P,N-pincer with a bridging $\mu$-P-donor was synthesized and its coordination to $\mathrm{Cu}(\mathrm{I})$ in the presence of dicyano-stilbene yielded a supramolecular rectangle assembly (60) containing a total of four $\mathrm{Cu}(\mathrm{I})$, four aza[4] helicene moieties, two dicyano-stilbene bridges and two dppe ligands around the $\mathrm{Cu}(\mathrm{I})$ atoms. ${ }^{80}$ The $\mathrm{X}$ ray crystallographic structure of $\mathbf{6 0}$ evidenced several sets of $\pi-\pi$ stacking interactions that stabilized the supramolecular architecture in the solid sate. Note however that $i$ ) such a structure probably undergoes fast exchange processes in 
solution, ii) the aza[4]helicene units possess overall planar geometry.

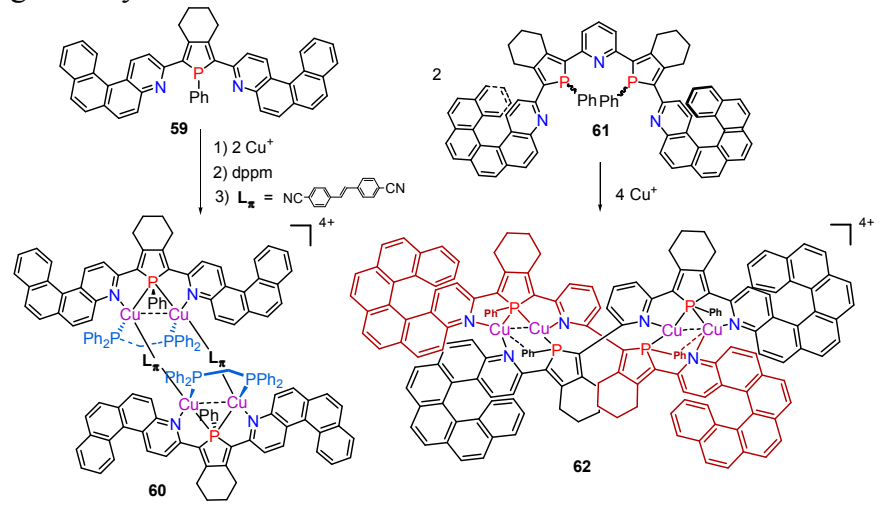

Scheme 16. Coordination-driven synthesis of supramolecular rectangle $\mathbf{6 0}$ using bis-aza4] helicene-phosphole $59^{80}$ and helicate $\mathbf{6 2}$ from helicand $61 .{ }^{81}$

To go one step further, multitopic 2,6-bis(aza[6]helicenephosphole)-pyridine $\mathbf{6 1}$ was prepared and appeared well-suited to generate structural diversity within helicate chemistry since it acted as a N,P,N,P,N-helicand upon an original coordination mode on $\mathrm{Cu}^{\mathrm{I}}$-dimers. ${ }^{48,81}$ The presence of the enantiopure $M$ - or $P$-helicene moieties allowed to prepare enantiopure helicates $M$ - and $P$-62, which closely assembled two helicene-capped helicands 61 around four $\mathrm{Cu}(\mathrm{I})$ centers, and to study their chiroptical properties. Theoretical calculations evidenced the efficient chiral induction from azahelicene moieties to the $\mathrm{Cu}^{\mathrm{I}}$ helicate core and emphasized the presence of helicand-tohelicand charge transfer (LLCT type) transitions that significantly impacted the ECD active bands although no MLCT was found.

In 1999, phtalocyanines such as 63 (Figure 13) fused to four non racemic [7]helicene units and bearing long chains have been prepared and studied by Katz, Persoons and collaborators. These molecules have shown to aggregate in appropriate EtOH$\mathrm{CHCl}_{3}$ solvent mixtures. ${ }^{82}$ Chiral Langmuir-Blogett films were prepared and displayed very strong second-order NLO activity. Although 2,2'-bipyridines are among the most widely used ligands in transition metal complexes, very little is known about helicenes bearing 2,2'-bi-pyridine and their coordination behavior. ${ }^{83-86}$ Katz reported in 1999 the synthesis of [8] helicene 64 acting as a bis-1,4- $N, N$-chelating ligand (Figure 13) and its coordination to rhenium(I) and copper(I) examined. ${ }^{85}$ Although the ECD spectra were briefly reported, the stereoselectivity issues were not examined in details.

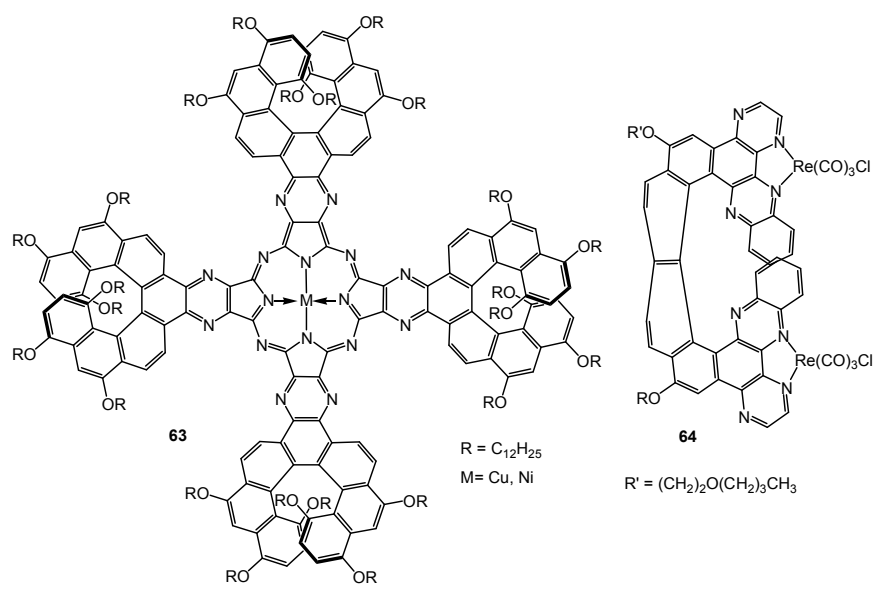

Figure 13. Phtalocyanine 63 capped with [7]helicene and displaying strong NLO activity $^{82}$ and rhenium(I) complex 64 of a [8] helicene acting as a bis-1,4- $N, N^{\prime}-$ chelate ligand. ${ }^{85}$

Finally, soluble helical conjugated ladder polymers 66 with average molecular weight of $7000 \mathrm{~g} / \mathrm{mol}$ were prepared by reaction of 1,2-phenylenediamine with enantiopure [6]helicene derivative 65 in the presence of a metallic ion, through the wellknown salophen coordination chemistry (Figure 14a). ${ }^{87,88}$ It was shown by molecular modelling that the $\mathrm{Ni}$ polymer complex bearing methoxy groups displayed a helical structure (Figure $14 \mathrm{~b})$ and that its extended $\pi$-conjugation resulted in a strong ECD signature at low energy (around $600 \mathrm{~nm}$ ) corresponding to MLCT-type transitions (Figure 14c).

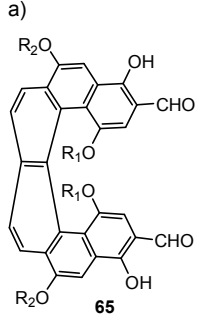

b)

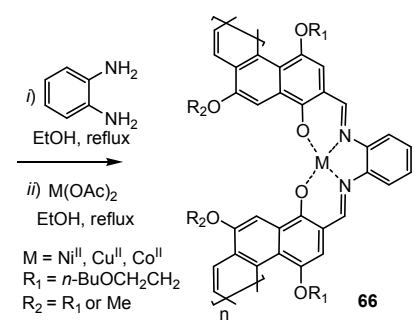

c)
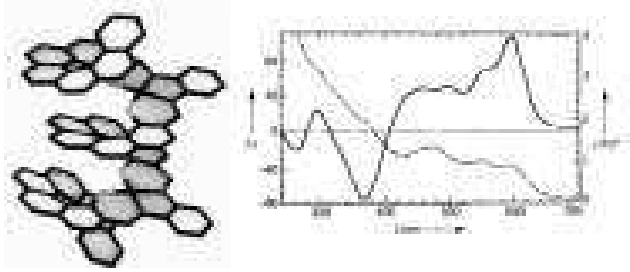

Figure 14. a) Synthesis of helical conjugated ladder polymers 66. b) Model of an all helical complex with two salenophen units and three helices. ${ }^{87,88} \mathrm{C}$ ) $\mathrm{CD}$ spectrum of polymer complex 66 bearing OMe groups. Adapted with permission from ref. 87 .

\section{Conclusion}

Throughout this review, we have reported many examples of helicene derivatives capped with a diversity of functional groups exhibiting efficient coordinating ability, such as cyclopentadienyl, alkynyl, vinyl, phenyl-pyridyl, cyano, 
phosphane, phosphite, heteroatoms, ... These helical $\pi$ conjugated ligands can in turn be involved in simple and wellknown coordination or organometallic chemistry. Such strategy consisting of combining helicene chemistry and transition metals has many advantages. It enables to conceive uncommon helicene-based transition metal architectures. Furthermore, reacting polycyclic helical aromatic molecules with metallic ions can significantly alter their electronic density distribution and modify their properties. The carefully chosen metal thus has a great impact on the helicene properties. Firstly, it directly impacts the chiroptical properties, i.e. specific and molar rotations, and electronic circular dichroism spectra. Secondly, new properties can appear, such as non polarized and circularly polarized luminescence, NLO activity, catalytic activity, redox switching, and conductivity. Thirdly, new fundamental aspects of chirality may appear, such as the cis-trans isomerism influenced by the enantiopurity of the helicene ligand, or dynamic isomerization processes. Finally, the stereochemical outcomes of the coordination processes ${ }^{89-95}$ are a fundamental part of the work and have to be controlled and well-understood, with the precious help of theoretical calculations. ${ }^{96}$ Further developments on the coordination behavior of helicene ligands at the molecular level may help to better understand other systems with higher level of complexity such as twodimensional chiral systems, aggregates, nanoparticles, ... All these aspects make this field of research one of constantly growing interest with several applications envisioned.

\section{Acknowledgements}

We thank the Ministère de l'Education Nationale, de la Recherche et de la Technologie, the Centre National de la Recherche Scientifique (CNRS), the ANR (ANR-12-BS070004-METALHEL-01 and ANR-10-BLAN-724-1NCPCHEM). J.C. warmly thanks Prof. Régis Réau for his scientific contribution and for longstanding fruitful discussions.

\section{Notes and references}

${ }^{a}$ Institut des Sciences Chimiques de Rennes, UMR 6226, Campus de Beaulieu, CNRS-Université de Rennes 1, 35042 Rennes Cedex, France. E-mail: jeanne.crassous@univ-rennes1.fr

${ }^{\dagger}$ We call a [n]helicene a helicenic structure composed of $\mathrm{n}$ ortho-fused aromatic rings, being either benzene, cyclopentadiene, pyridine, ... The term metallahelicene is used when a metal is incorporated with an orthofused $\pi$-helical backbone through a C-M $\sigma$ bond.

${ }^{*}$ Specific rotations $[\alpha]_{D}^{T}$ units are $\operatorname{deg} /\left[\mathrm{dm}\left(\mathrm{g} / \mathrm{cm}^{-3}\right)\right]$ and molar rotations $[\phi]_{D}^{T}$ units are deg $\mathrm{cm}^{2} \mathrm{dmol}^{-1}$.

$[\phi]_{D}^{T}=\frac{[\alpha]_{D}^{T} \times M W}{100}$, where $T$ is the temperature, $D$ the sodium line and $M W$

the molecular weight. For general definitions see: E. L. Eliel, S. H. Wilen,

Stereochemistry of Organic Compounds, J. Wiley \& Sons, 1993.
${ }^{1}$ Y. Shen, C. -F. Chen, Chem. Rev., 2012, 112, 1463-1535.

${ }^{2}$ M. Gingras, Chem. Soc. Rev., 2013, 42, 1051-1095.

${ }^{3}$ D. Amabilino, Chirality at the Nanoscale, Nanoparticles, Surfaces, Materials and more, Wiley-VCH, 2009.

${ }^{4}$ B. L. Feringa, W.R. Browne, Molecular Switches, 2nd edition, Wiley-VCH, 2011

${ }^{5}$ I. G. Stará, I. Starý, in: Science of Synthesis (Eds.: J.S. Siegel, Y. Tobe), Thieme, Stuttgart, 2010, 45, pp. 885-953.

${ }^{6}$ F. Dumitrascu, D. G. Dumitrescu, I. Aron, ARKIVOC, 2010, 1, 1-32.

${ }^{7}$ A. Rajca, M. Miyasaka, in Functional Organic Materials (Eds.: T. J. J. Müller,

U. H. F. Bunz), Wiley-VCH, Weinheim, 2007, pp. 543-577.

${ }^{8}$ A. Urbano, Angew. Chem. Int. Ed., 2003, 42, 3986-3989.

${ }^{9}$ T. J. Katz, Angew. Chem. Int. Ed., 2000, 39, 1921-1923.

${ }^{10}$ R. H. Martin, Angew. Chem. Int. Ed.,1974, 13, 649-659.

${ }^{11}$ J. Bosson, J. Gouin, J. Lacour, Chem. Soc. Rev., 2014, 43, 2824-2840.

${ }^{12}$ H. Wynberg, Acc. Chem. Res., 1971, 4, 65-73.

${ }^{13} \mathrm{C}$. Elschenbroich, Organometallics, Wiley VCH, 2006.

${ }^{14}$ H. Le Bozec, V. Guerchais, Molecular Organometallic Materials for Optics: 28 (Topics in Organometallic Chemistry), Springer Berlin Heidelberg, 2009.

${ }^{15}$ T. J. Katz, W. Slusarek, J. Am. Chem. Soc., 1979, 101, 4259-4267.

${ }^{16}$ T. J. Katz, J. Pesti, J. Am. Chem. Soc., 1982, 104, 346-347.

${ }^{17}$ J. C. Dewan, Organometallics, 1983, 2, 83-88

${ }^{18}$ A. Sudhakar, T. J. Katz, J. Am. Chem. Soc., 1986, 108, 179-181

${ }^{19}$ Note that the absolute configurations $P-(+)$ and $M-(-)$ can be usually assigned to helicene derivatives from their strong typical signature in their circular dichroism spectra. See for example: F. Furche, R. Ahlrichs, C. Wachsmann, E. Weber, A. Sobanski, F. Vogtle, S. Grimme, J. Am. Chem. Soc., 2000, 122, 1717-1724 and references therein. See also ref. 1.

${ }^{20}$ A. M. Gilbert, T. J. Katz, W. E. Geiger, M. P. Robben, A. L. Rheingold, J. Am. Chem. Soc., 1993, 115, 3199-3211.

${ }^{21}$ A. Sudhakar, T. J. Katz, B.-W. Yang, J. Am. Chem. Soc., 1986, 108, 2790-2791.

${ }^{22}$ P. Aguirre-Etcheverry, D. O'Hare, Chem. Rev., 2010, 110, 4839-4864.

${ }^{23}$ T. J. Katz, A. Sudhakar, M. F. Teasley, A. M. Gilbert, W. E. Geiger, M. P. Robben, M. Wuensch, M. D. Ward, J. Am. Chem. Soc., 1993, 115, 3182-3198.

${ }^{24}$ F. Pammer, Y. Sun, M. Pagels, D. Weismann, H. Sitzmann, W. R. Thiel, Angew. Chem. Int. Ed., 2008, 47, 3271-3274.

${ }^{25}$ F. Pammer, Y. Sun, M. Sieger, J. Fiedler, B. Sarkar, W. R. Thiel, Organometallics, 2010, 29, 6165-6168

${ }^{26}$ F. Pammer, Y. Sun, W. R. Thiel, Inorg. Chim. Acta, 2011, 374, 205-210.

${ }^{27}$ A. Latorre, A. Urbano, M. C. Carreno, Chem. Commun., 2011, 47, 8103-8105.

${ }^{28}$ C. M. Alvarez, H. Barbero, L. A. Garcia-Escudero, J. M. Martín-Alvarez, C. Martínez-Perez, D. Miguel, Inorg. Chem., 2012, 51, 8103-8111.

${ }^{29}$ J. O. C. Jiménez-Halla, J. Robles, M. Sola, Organometallics, 2008, 27, 5230-5240.

${ }^{30}$ S. Saini, B. M. Deb, Indian J. Chem., 2007, 46A, 9-15.

${ }^{31}$ M. P. Johansson, M. Patzschke, Chem. Eur. J., 2009, 15, 13210-13218.

${ }^{32}$ M. J. Fuchter, J. Schaefer, D. K. Judge, B. Wardzinski, M. Weimar, I. Krossing, Dalton Trans., 2012, 41, 8238-8241.

${ }^{33}$ M. Munakata, L. P. Wu, G. L. Ning, T. Kuroda-Sowa, M. Maekawa, Y. Suenaga, N. Maeno, J. Am. Chem. Soc., 1999, 121, 4968-4976.

${ }^{34}$ Z. Gomez-Sandoval, E. Pena, C. Fonseca Guerra, F. M. Bickelhaupt, M. A. Mendez-Rojas, G. Merino, Inorg. Chem., 2009, 48, 2714-2716

${ }^{35}$ K. Costuas, S. Rigaut, Dalton Trans., 2011, 40, 5643-5658.

${ }^{36}$ E. Anger, M. Srebro, N. Vanthuyne, L. Toupet, S.Rigaut, C. Roussel, J.

Autschbach, J.Crassous, R. Réau, J. Am. Chem. Soc., 2012, 134, 15628-15631.

${ }^{37}$ E. Anger, M. Srebro, N. Vanthuyne, C. Roussel, L. Toupet, J. Autschbach, R.

Réau, J. Crassous, Chem. Comm., 2014, 50, 2854-2856.

${ }^{38}$ F. Rose-Munch, M. Li, E. Rose, J. -C. Daran, A. Bossi, E. Licandro, P. R. Mussini, Organometallics, 2012, 31, 92-104.

${ }^{39}$ H. Yersin, Highly Efficient OLEDs with Phosphorescent Materials, Wiley VCH, 2008.

${ }^{40}$ L. Norel, M. Rudolph, N. Vanthuyne, J. A. G. Williams, C. Lescop, C. Roussel, J. Autschbach, J. Crassous, R. Réau, Angew. Chem. Int. Ed., 2010, 49, 99-102.

${ }^{41}$ E. Anger, M. Rudolph, L. Norel, S. Zrig, C. Shen, N. Vanthuyne, L. Toupet, J. A. G. Williams, C. Roussel, J. Autschbach, J. Crassous, R. Réau, Chem. Eur. J., 2011, 17, 14178-14198.

${ }^{42}$ C. Shen, E. Anger, M. Srebro, N. Vanthuyne, K. K. Deol, T. D. Jefferson Jr., G. Muller, J. A. G. Williams, L. Toupet, C. Roussel, J. Autschbach, R. Réau, J. Crassous, Chem. Sci., 2014, 5, 1915-1927.

${ }^{43}$ S. Abbate, G. Longhi, F. Lebon, E. Castiglioni, S. Superchi, L. Pisani, F. Fontana, F. Torricelli, T. Caronna, C. Villani, R. Sabia, M. Tommasini, A. Lucotti, D. Mendola,

A. Mele, D. A. Lightner, J. Phys. Chem. C, 2014, 118, 1682-1695

${ }^{44}$ E. Anger, M. Rudolph, C. Shen, N. Vanthuyne, L. Toupet, C. Roussel, J. Autschbach, J. Crassous, R. Réau, J. Am. Chem. Soc., 2011, 133, 3800-3803.

${ }^{45}$ C. Shen, E. Anger, M. Srebro, N. Vanthuyne, L. Toupet, C. Roussel, J. Autschbach, R. Reau, J. Crassous, Chem. Eur. J., 2013, 19, 16722-16728.

${ }^{46}$ L. Chassot, E. Muller, A. Von Zelewsky, Inorg. Chem. 1984, 23, 4249-4253.

${ }^{47}$ O. Crespo, B. Eguillor, M. A. Esteruelas, I. Fernandez, J. Garcia-Raboso, M. Gomez-Gallego, M. Martin-Ortiz, M. Olivan, M. A. Sierra, Chem. Comm., 2012, 48, 5328-5330.

${ }^{48}$ J. -M. Lehn, Supramolecular Chemistry: Concepts and Perspectives, VCH, Weinheim 1995 . 
${ }^{49}$ J. -P. Sauvage, Transition metals in supramolecular chemistry, J. Wiley \& Sons, Chichester, 1994.

${ }^{50}$ For a recent review on helical-chiral small molecules in asymmetric catalysis see: M. J. Narcis, N. Takenaka, Eur. J. Org. Chem., 2014, 21-34.

${ }^{51}$ A. Terfort, H. Görls, H. Brunner, Synthesis, 1997, 79-86.

${ }^{52}$ M. T. Reetz, E. W. Beuttenmüller, R. Goddard, Tetrahedron Lett., 1997, 38, 3211 3214.

${ }^{53}$ M. T. Reetz, S. Sostmann, J. Organomet. Chem., 2000, 603, 105-109.

${ }^{54}$ S. D. Dreher, T. J. Katz, K.-C. Lam, A. L. Rheingold, J. Org. Chem., 2000, 65, 815-822.

${ }^{55}$ H. Okubo, M. Yamaguchi, C. Kabuto, J. Org. Chem., 1998, 63, 9500-9509.

${ }^{56}$ D. Nakano, M. Yamaguchi, Tetrahedron Lett., 2003, 44, 4969-4971.

${ }^{57}$ Z. Krausova, P. Sehnal, B. P. Bondzic, S. Chercheja, P. Eilbracht, I. G. Stara, D. Saman, I. Stary, Eur. J. Org. Chem., 2011, 3849-3857.

${ }^{58}$ K. Yavari, P. Aillard, Y. Zhang, F. Nuter, P. Retailleau, A. Voituriez, A. Marinetti, Angew. Chem. Int. Ed., 2014, 53, 861-865.

${ }^{59}$ K. Yavari, P. Retailleau, A. Voituriez, A. Marinetti, Chem. Eur. J., 2013, 19, 99399947.

${ }^{60}$ S. Cauteruccio, A. Loos, A. Bossi, M. C. Blanco Jaimes, D. R. Dova, F. S. Prager,

A. Dreuw, E. Licandro, A. S. K. Hashmi, Inorg. Chem., 2013, 52, 7995-8004.

${ }^{61}$ M. Monteforte, S. Cauteruccio, S. Maiorana, T. Benincori, A. Forni, L.

Raimondi, C. Graiff, A. Tiripicchio, G. R. Stephenson, E. Licandro, Eur. J. Org. Chem., 2011, 5649-5658.

${ }^{62}$ I. Sato, R. Yamashima, K. Kadowaki, J. Yamamoto, T. Shibata, K. Soai, Angew. Chem. Int. Ed., 2001, 40, 1096-1098.

${ }^{63}$ T. Kawasaki, K. Suzuki, E. Licandro, A. Bossi, S. Maiorana, K. Soai,

Tetrahedron: Asymmetry, 2006, 17, 2050-2053

${ }^{64}$ R. El Abed, F. Aloui, J. P. Genet, B. Ben Hassine, A. Marinetti, J. Organomet.

Chem, 2007, 692, 1156-1160.

${ }^{65}$ F. Aloui, B. Ben Hassine, Tetrahedron Lett., 2009, 50, 4321-4323.

${ }^{66}$ M. H. Garcia, P. Florindo, M. M. Piedade, S. Maiorana, E. Licandro, Polyhedron, 2009, 28, 621-629.

${ }^{67}$ Y. Yang, R.C. da Costa, D.-M. Smilgies, A.J. Campbell, M.J. Fuchter, Adv. Mater. 2013, 15, 2624-2628.

${ }^{68}$ Y. Yang, R.C. da Costa, M.J. Fuchter, A.J. Campbell, Nature Photonics, 2013, 7, 634-638.

${ }^{69}$ See for example S. Abbate, T. Caronna, A. Longo, A. Ruggirello, V. T. Liveri, J.

Phys. Chem. B, 2007, 111, 4089-4097.

${ }^{70}$ J. V. Chocholousova, J. Vacek, A. Andronova, J. Misek, O. Songis, M. Samal, I

G. Stara, M. Meyer, M. Bourdillon, L. Pospisil, I. Stary, Chem. Eur. J., 2014, 20, 877 -

893 and references therein.

${ }^{71}$ J. Misek, F. Teply, I. G. Stara, M. Tichy, D. Saman, I. Cisarova, P.Vojtisek, I. Stary, Angew. Chem. Int. Ed., 2008, 47, 3188-3191.

${ }_{72}$ J. Misek, M. Tichy, I. G. Stara, I. Stary, D. Schroeder, Collect. Czech. Chem. Commun., 2009, 74, 323-333.

${ }^{73}$ I. Alkorta, F. Blanco, J. Elguero, D. Schröder, Tetrahedron: Asymmetry, 2010, 21, 962-968.

${ }^{74}$ D. Mendola, N. Saleh, N. Vanthuyne, C. Roussel, L. Toupet, F. Castiglione, T.

Caronna, A. Mele, J. Crassous, Angew. Chem. Int. Ed., 2014, ASAP.

${ }^{75}$ J. Crassous, R. Réau, Dalton Trans., 2008, 6865-6876.

${ }^{76}$ J. Crassous, C. Lescop, R. Réau, in Phosphorus Chemistry: Catalysis and Material Science Applications, Series: Catalysis by Metal Complexes (CMCO), Springer, 2011, 11, pp.367-399.

${ }_{77}$ W. Shen, S. Graule, J. Crassous, C. Lescop, H. Gornitzka, R. Réau, Chem. Comm. 2008, 850-852.

${ }^{78}$ S. Graule, M. Rudolph, N. Vanthuyne, J. Autschbach, C. Roussel, J. Crassous, R. Réau, J. Am. Chem. Soc., 2009, 131, 3183-3185.

${ }^{79}$ S. Graule, M. Rudolph, W. Shen, C. Lescop, J. A. G. Williams, J. Autschbach, J. Crassous, R. Réau, Chem. Eur. J., 2010, 16, 5976-6005.

${ }^{80}$ A. I. Aranda Perez, T. Biet, S. Graule, T. Agou, C. Lescop, N. R. Branda, J. Crassous, R. Réau, Chem. Eur. J., 2011, 17, 1337-1351.

${ }^{81}$ V. Vreshch, M. El Sayed Moussa, B. Nohra, M. Srebro, N. Vanthuyne, C. Roussel, J. Autschbach, J. Crassous, C. Lescop, R. Réau, Angew. Chem. Int. Ed., 2013, 52, 1968 1972 .

${ }^{82}$ J. M. Fox, T. J. Katz, S. Van Elshocht, T. Verbiest, M. Kauranen, A. Persoons, T. Thongpanchang, T. Krauss, L. Brus, J. Am. Chem. Soc., 1999, 121, 3453-3459.

${ }^{83}$ K. Deshayes, R. D. Broene, I. Chao, C. B. Knobler, F. Diederich, J. Org. Chem., 1991, 56, 6787-6791.

${ }_{84}$ J. Chen, B. Captain, N. Takenaka, Org. Lett., 2011, 13, 1654-1657.

${ }^{85}$ N. Takenaka, R. S. Sarangthem, B. Captain, Angew. Chem. Int. Ed., 2008, 47 9708-9710.

${ }^{86}$ J. M. Fox, T. J. Katz, J. Org. Chem., 1999, 64, 302-305.

${ }^{87}$ Y. Dai, T. J. Katz, D. A. Nichols, Angew. Chem. Int. Ed., 1996, 35, 2109-2111.

${ }^{88}$ Y. Dai, T. J. Katz, J. Org. Chem., 1997, 62, 1274-1285.

89 A. von Zelewsky, Stereochemistry of Coordination Compounds, J. Wiley\&Sons, Chichester, 1996.

${ }^{90}$ A. Amouri, M. Gruselle, Chirality in Transition Metal Chemistry: Molecules,

Supramolecular Assemblies and Materials, Wiley-VCH, 2009.

${ }^{91}$ J. Crassous, Chem. Comm., 2012, 48, 9684-9692.

${ }_{92}$ J. Crassous, Chem. Soc. Rev., 2009, 38, 830-845.

${ }^{93}$ U. Knof, A. von Zelewsky, Angew. Chem., Int. Ed., 1999, 38, 302-322.

${ }^{94}$ L. Gong, M. Wenzel, E. Meggers, Acc. Chem. Res., 2013, 46, 2635-2644.

${ }^{95}$ E. C. Constable, Chem. Soc. Rev., 2013, 42, 1637-1651.
${ }^{96}$ J. Autschbach, in Comprehensive Chiroptical Spectroscopy - Instrumentation, Methodologies, and Theoretical Simulations (Eds. N. Berova, P. L. Polavarapu, K. Nakanishi, R. W. Woody), J. Wiley \& Sons, Hoboken, 2012, pp. 593-642. 